\title{
Influence of a Great Plains Urban Environment on a Simulated Supercell
}

\author{
LARISSA J. REAMES \\ National Severe Storms Laboratory, Norman, Oklahoma \\ DAVID J. STENSRUD \\ Department of Meteorology and Atmospheric Science, The Pennsylvania State University, University Park, Pennsylvania
}

(Manuscript received 28 September 2017, in final form 21 March 2018)

\begin{abstract}
The effect of urban areas on weakly forced precipitation systems has been studied extensively. However, interactions between urban areas and strongly forced convection, such as supercells, remain relatively unexamined. The present study uses simulations of a supercell to quantify the impacts of a large plains urban area on the evolution and strength of a supercell. An initial ensemble of simulations (CTRLE) of a supercell over homogeneous land use is performed using the WRF-ARW Model. Additionally, 108 simulations are conducted in which the land-use pattern of Dallas-Ft. Worth, Texas, is placed inside the model domain, with the city center shifted to be in or near the path of the supercell. Simulations with urban areas are compared to CTRLE, with the aid of hierarchical clustering analysis to form statistically similar groups of simulations. Clustering analyses identify groups of ensemble members with closely located urban areas that have similar patterns of $0-1-\mathrm{km}$ updraft helicity and near-surface minimum temperature and maximum wind speeds. Comparison of these groups of ensemble members to CTRLE suggests the urban area has a significant impact on storm characteristics, particularly on low-level rotation and mesocyclone track. Simulations where the storm passes to the north of or directly over the city center late in its life cycle deviate most significantly from CTRLE. In these members, low-and midlevel mesocyclone strength increases, and the mesocyclone tracks farther south when compared to CTRLE.
\end{abstract}

\section{Introduction}

Urban areas modify boundary layer processes through the replacement of natural vegetation with urban surfaces. The unique thermal properties of manmade materials (e.g., surface albedo and emissivity; Oke 1976, 1981, 1982; Arnfield 2003; Barlow 2014) typically result in urban areas that are warmer than their surroundings, especially at night. This effect, often called the urban heat island (UHI; Oke 1982), has been observed in numerous cities (e.g., Gedzelman et al. 2003; Yow and Carbone 2006; Alonso et al. 2007; Yang et al. 2013; Hu et al. 2016). Urbanized locations also generally have less transpiring vegetation than rural areas; hence, urban environments tend to be drier, particularly during the daytime of warm weather months. However, this warm, dry pattern can be modulated by various local and large-scale conditions (Hage 1975; Landsberg 1981;

Corresponding author: Dr. Larissa J. Reames, larissa.reames@ noaa.gov
Ackerman 1987; Lee 1991; Unkašević et al. 2001; Dou et al. 2015). Although not as well documented, in situ measurements also document slower wind speeds in urban areas due to increased surface roughness, most prominently during the day, when turbulent mixing is most intense and rural wind speeds are at their diurnal peak (Bornstein and Johnson 1977; $\mathrm{Hu}$ et al. 2016; Reames and Stensrud 2017, hereafter RS17).

Atmospheric modifications by urban areas can affect storm-scale weather phenomena. Enhanced convergence on the outskirts of an urban area, as a result of increased surface roughness, can result in precipitation enhancement in and near the urban area (e.g., Bornstein and Lin 2000; Thielen et al. 2000), as can UHI-induced destabilization over and downwind of cities (e.g., Shepherd et al. 2002; Shepherd and Burian 2003; Shepherd 2006; Mote et al. 2007; Baik et al. 2007). Recent observational studies find significant $(10 \%-30 \%)$ precipitation increases over and downwind of cities (e.g., Lacke et al. 2009; Shepherd et al. 2010; Li et al. 2011; Ganeshan et al. 2013; Seino et al. 2018; McLeod 
et al. 2017). In comparing rain gauge measurements in and around Houston, Texas, Burian et al. (2005) show that warm season rainfall increased by $25 \%$ from $1950-58$ to $1984-99$, suggesting that the urban effect on downwind precipitation is affected by urban size. Modeling studies (e.g., Li et al. 2011; Wang et al. 2014; Yang et al. 2014b) have suggested that this additional precipitation is a result of more (less) frequent heavy (light) rainfall events. Additionally, observational (e.g., Loose and Bornstein 1977; Bornstein and Lin 2000; Niyogi et al. 2011) and modeling (e.g., Niyogi et al. 2011; Miao et al. 2011; Yang et al. 2014b) investigations have suggested that the increased surface roughness of the urban canopy can cause a bifurcation or diversion of precipitation systems, further modifying precipitation distribution.

The majority of these studies involve warm season precipitation that forms under generally benign synoptic conditions. Using a climatology of lightning flashes near New York City, Yeung et al. (2015) find that while organized thunderstorms associated with strong dynamic forcing change structure and initiate new cells more frequently over the urban area, these storms do not split as they approach from the west. Yang et al. (2014a) reach a similar conclusion using simulations of strongly forced convective systems in the Milwaukee area, finding negligible large-scale differences in precipitation patterns when urban areas are removed from their domain. The results of these studies differ from those of studies that consider weakly forced convection, suggesting that interactions between urban areas and organized, forced convection merit further investigation.

As yet unexplored are the effects that urban areas could have on severe organized convection, particularly supercells. Recent research involving supercells has focused on properties of the lowest $500-1000 \mathrm{~m}$ of the PBL, especially the role played by vertical wind shear near the surface in low-level mesocyclone strength and tornadogenesis. Wicker (1996), using VORTEX sounding data as guidance for idealized simulations, found that slower, veered storm inflow significantly influenced the development of simulated low-level mesocyclones. Similarly, Thompson and Edwards (2000) noted a prominent low-level hodograph "kink" separating primarily nearsurface vertical speed shear from principally directional shear above in some environments of significantly tornadic supercells. Subsequent analyses of proximity soundings and modeling investigations suggest that the properties of the PBL below this "kink" (i.e., typically below $500 \mathrm{~m}$ ) discriminate tornadic from nontornadic environments better than traditional deep-layer metrics used to identify environments supportive of supercells (e.g., Esterheld and Giuliano 2008; Togstad et al. 2011; Nowotarski and Jensen 2013). Using idealized simulations, Markowski et al. (2012) and Markowski and Richardson (2014) show that environmental shear in the lowest few hundred meters of the PBL is dynamically beneficial to the development of a supercell's low-level mesocyclone. They hypothesize that stronger near-surface shear lowers the base of the midlevel mesocyclone, thereby enhancing the dynamic vertical perturbation pressure gradient force. This results in greater stretching of negatively buoyant (and thus, resistant to lifting) near-surface outflow parcels that possess cyclonic vertical vorticity $(\zeta)$, thereby strengthening the low-level mesocyclone. Examining properties even closer to the surface, it has been shown that surface friction can intensify tornadoes by preventing the development of cyclostrophic balance and thereby promoting radial convergence (e.g., Rotunno 1979; Howells et al. 1988; Lewellen 1993). Additionally, recent simulations (Schenkman et al. 2012; Xu et al. 2015) have suggested that friction can also act as a source of vorticity in storm inflows, rather than solely serving to enhance vorticity generated by other means.

Given the well-documented ability of urban areas to affect the lowest levels of the atmosphere and the dependence of supercell characteristics upon the properties of this layer, it is hypothesized here that urban areas affect supercell strength and morphology. To investigate this, the present study uses the Advanced Research Weather Research and Forecasting (WRF-ARW; Skamarock and Klemp 2008) Model to investigate the effects of a large urban environment on the evolution and strength of a simulated isolated supercell. The land-use pattern of a large, southern plains city-Dallas-Fort Worth (DFW), Texas-is placed in 108 unique, regularly spaced locations throughout the simulation domain. A model simulation is run for each city location, and all simulations produce a supercell storm. Thus, differences among ensemble members are used to glean information about the sensitivity of urban-storm interactions to city location relative to storm path. The next section provides further details of the simulation procedure and analysis techniques, followed in section 3 by an overview of model results from a simulation that does not contain any urban areas. Results from the 108 urban simulations are presented in section 4 and summarized in section 5 .

\section{Methods}

\section{a. Model configuration and simulation descriptions}

Simulations are performed using the WRF-ARW version 3.6.1. Three one-way-nested domains (Table 1) are used with $4.5-, 1.5-$, and $0.5-\mathrm{km}$ horizontal grid spacing and domain sizes of $300 \times 300,399 \times 399$, and $498 \times 498$, respectively (Fig. 1a). All domains have 119 vertical 
TABLE 1. Simulation domain and parameterization specifications.

\begin{tabular}{lccc}
\hline \hline & $\mathrm{d} 01$ & $\mathrm{~d} 02$ & $\mathrm{~d} 03$ \\
\hline Horizontal grid size & $300 \times 300$ & $399 \times 399$ & $498 \times 498$ \\
Horizontal grid spacing (km) & 4.5 & 1.5 & 0.5 \\
Vertical levels & \multicolumn{3}{c}{119} \\
Time steps (s) & 6 & 2 & 1 \\
Microphysics & \multicolumn{3}{c}{ NSSL } \\
LW radiation & \multicolumn{3}{c}{ New Goddard } \\
SW radiation & \multicolumn{3}{c}{ YSU } \\
PBL scheme & \multicolumn{3}{c}{ Modified Noah LSM } \\
Land surface scheme & \multicolumn{3}{c}{. }
\end{tabular}

terrain-following grid points, spaced at $\sim 50 \mathrm{~m}$ near the surface and stretching to $\sim 150-\mathrm{m}$ spacing at $800 \mathrm{hPa}$ ( $\sim 2 \mathrm{~km}$ AGL) and above. Approximately 20 vertical levels are within the lowest $1.0 \mathrm{~km}$ AGL, providing fine vertical resolution in the convective boundary layer (CBL).
All three domains employ the same parameterization options: Goddard short- and longwave radiation schemes (Chou and Suarez 1999; Chou et al. 2001; Matsui et al. 2007), a modified version of the Noah land surface model (LSM; Chen and Dudhia 2001; Ek et al. 2003; RS17), the Yonsei University (YSU) PBL scheme (Noh et al. 2003) and corresponding MM5 MoninObukhov surface layer scheme (Monin and Obukhov 1954; Paulson 1970; Dyer and Hicks 1970; Webb 1970), and the double-moment NSSL microphysics scheme (Mansell et al. 2010), which uses six hydrometeor classes and predicts graupel density. The YSU scheme is selected, as it yields PBL properties and depths that agree well with observations and because it has been shown to perform well in plains severe weather environments (Coniglio et al. 2013; Clark et al. 2015). An urban canopy model (UCM) is not used to represent urban areas
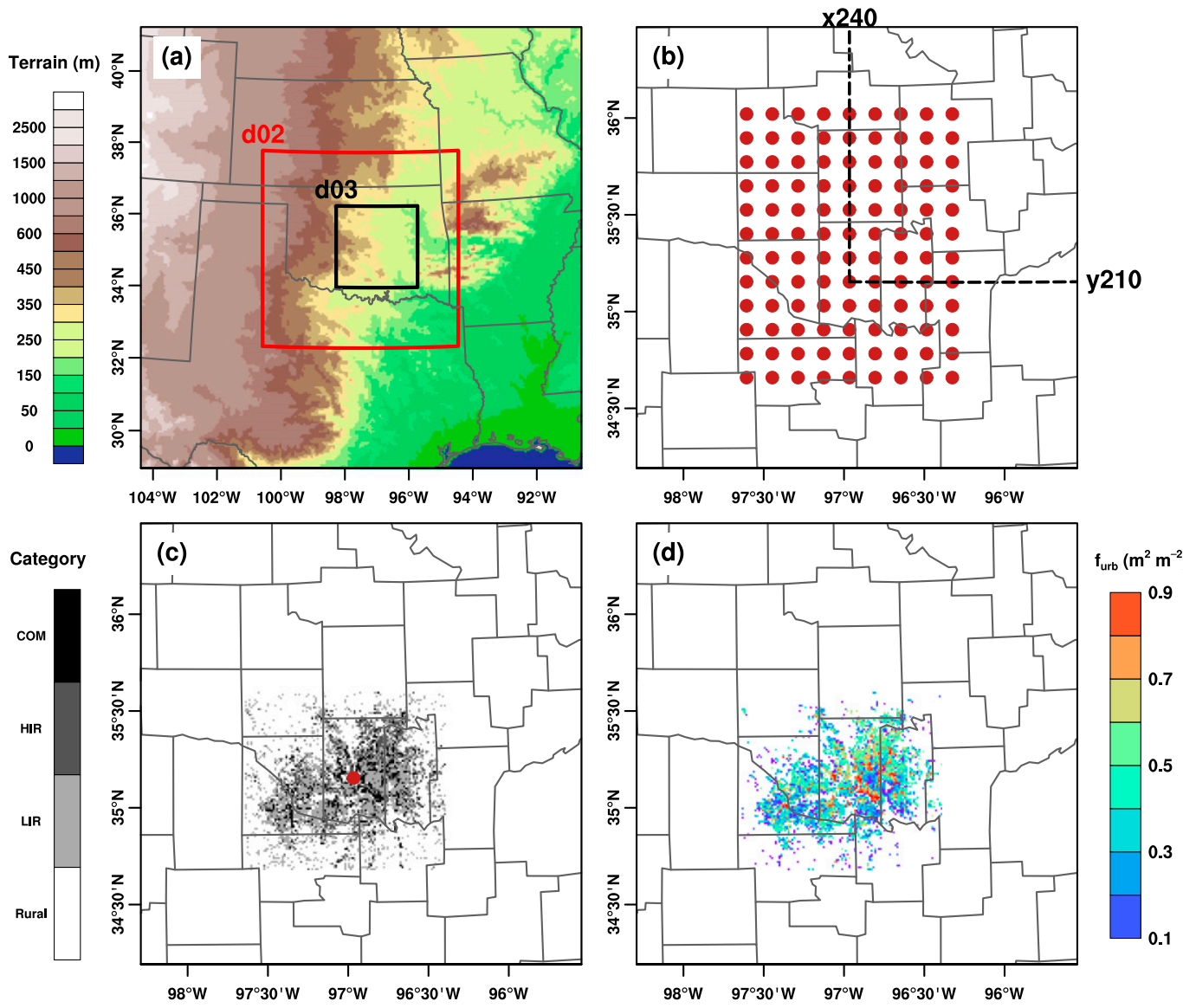

FIG. 1. (a) Domain locations used for all simulations in this study. The plotted area is encompassed by d01, and the red and black boxes indicate $\mathrm{d} 02$ and d03, respectively. Terrain height is shaded, and state boundaries are in gray. (b) Grid of 108 simulation urban locations (red dots), plotted according to the center of urban fraction mass for each simulation in d03. Oklahoma county lines are in black. (c) Urban land-use data for run x240.y210 are shaded according to the four urban categories: commercial (COM), high intensity residential (HIR), low intensity residential (LIR), and rural or nonurban. The center of mass location (red dot) of this city location corresponds to the dashed lines and labels in (b). (d) As in (c), but for urban fraction. 
because RS17 show that the single-layer UCM (SLUCM; Kusaka et al. 2001; Kusaka and Kimura 2004) - the only explicit UCM available in the WRF that is compatible with the YSU PBL scheme-is not appropriate for use in plains cities, particularly because of its poor prediction of urban wind speeds.

Each simulation is initialized at 0600 UTC (0000 LST) 31 May 2013 with a Rapid Refresh (RAP) analysis, supplemented by offline North American Land Data Assimilation-2 (NLDAS-2) $0.125^{\circ}$ Noah model soil moisture and temperature output (Xia et al. 2012), provided by the Goddard Earth Sciences Data and Information Services Center (GES DISC). Simulations are integrated for $24 \mathrm{~h}$ to 0600 UTC 1 June 2013 using time steps of 6,2 , and $1 \mathrm{~s}$ for $\mathrm{d} 01, \mathrm{~d} 02$, and $\mathrm{d} 03$, respectively, with lateral boundary conditions for d01 provided by hourly RAP analyses. In total, 118 separate simulations are performed: one with all grassland landcover type in d03 (CTRL); nine additional simulations, also with all grassland land cover, but with random, small-amplitude $(\sim 0.001$ where typical values are $\sim 0.3)$, zero-mean, normally distributed noise applied to the volumetric soil water content of the top soil layer (CTRLE); and 108 with the DFW urban area placed in one of 108 regularly spaced gridded locations in d03 (Fig. 1b). For each nonCTRL simulation, three-category urban land use (Fig. 1c) and urban fraction (Fig. 1d) of DFW, derived from 30-m National Land Cover Database (NLCD) land-cover (Homer et al. 2015) and impervious surface (Xian et al. 2011) data, respectively, are used to represent the characteristics of the DFW urban area. All other areas in d03 remain grassland, as in CTRL. The use of NCDC data for urban land cover and fraction follows that of RS17. The 108 simulations with the land use of DFW are referred to by the location of the mass-weighted center (with urban fraction used as the mass) of DFW relative to the southwest corner of d03. For example, the mass center of DFW in simulation x240.y183 would be 240 grid points $(120 \mathrm{~km})$ east and $183(91.5 \mathrm{~km})$ north of the southwest corner of $\mathrm{d} 03$ (Figs. 1b,c).

The purpose of the CTRLE simulations is to provide an initial condition ensemble against which to compare variable means across various groups of DFW simulations. If DFW simulation group averages are compared only to the CTRL run, small-scale features from CTRL can dominate the analysis. However, averaging over the CTRLE simulations makes comparative analyses less dependent on random variability from a single run and better elucidates the dominant difference signals. Soil moisture was chosen as the perturbed initial condition for the ensemble because the observed dry soil moisture bias over Oklahoma in NLDAS-2 data (Xia et al. 2014) may result in existing initial soil moisture errors. Additionally, varying soil moisture still preserves the homogeneous land use of the CTRL simulation. However, similar results should be expected, initializing the ensemble with perturbations to other variables. Henceforth, the slate of 10 simulations that use the CTRL land use (i.e., CTRL plus CTRLE) will be referred to as CTRLE; however, some analyses will only consider CTRL where appropriate.

This model configuration is used to simulate a real meteorological situation interacting with a relatively idealized land-use pattern and is not intended to reproduce exactly the events of 31 May 2013. This date, and the events that occurred on it, are irrelevant to the discussions presented here, and this date is chosen purely because the boundary conditions provided by NWP models on this date produce a relatively isolated, long-lived supercell in the chosen WRF configuration. While using the land use of Oklahoma City, instead of DFW, would be more geographically appropriate, the intention of using the much larger urban area of DFW is to maximize the magnitude and extent of urban effects, while still using the land-use pattern of an urban area that is appropriate for the southern Great Plains.

\section{b. HCA description}

Analyzing simulations in groups makes the resulting analyses more robust and less susceptible to noise that necessarily arises as a result of small-scale artifacts. While the various DFW simulations could be grouped simply using the latitudinal and/or longitudinal location of the urban area, there is no guarantee that such a clustering procedure yields groups whose members are most similar to each other. Hence, we perform hierarchical clustering analysis (HCA; Anderberg 1973; Alhamed et al. 2002) using variables that measure storm strength and evolution (e.g., rainfall, near-surface temperature, and wind speed) to determine which simulations should be grouped together. HCA can help identify potentially important relationships in highly complex datasets that could easily be overlooked otherwise, requires no a priori assumptions about how many clusters exist, and allows clusters and their secondary subclusters to be identified simultaneously (Wilks 2011). These qualities make HCA an ideal choice for the present study, and it has been used previously to draw insight from ensemble simulations (e.g., Yussouf et al. 2004; Nakaegawa and Kanamitsu 2006; Branković et al. 2008; Johnson et al. 2011b)

Let $\mathbf{X}=\left[x_{i j}\right], 1 \leq i \leq m, 1 \leq j \leq n$ be the data matrix of some variable taken from simulation output, where each $j$ th column represents an object (in this case, a simulation member), and each $i$ th row represents a forecast 
(a grid point in the horizontal plane). Hence, for the following analyses, $\mathbf{X} \in \mathrm{R}^{248004 \times 108}, x_{\star j}$ denotes the $j$ th object/simulation member across all $m$ forecast points, and $x_{i \star}$ denotes the $i$ th forecast point across all $n$ objects/ simulation members.

HCA uses either similarity or dissimilarity measures to quantify the distance between objects. The pairwise distances between all objects are calculated and arranged in the form of a square $n \times n$ matrix, where the $i j$ th entry denotes the distance between objects $i$ and $j$, and $n$ is the number of objects. For this study, the commonly employed Euclidean distance dissimilarity measure is selected for use, as tests using other similarity/ dissimilarity measures (e.g., correlation) produced results similar to those presented herein using Euclidian distance. The Euclidean distance $e_{i j}$ between two objects, $i$ and $j$, is defined as

$$
e_{i j}=\sqrt{\sum_{z=1}^{m}\left(x_{z i}-x_{z j}\right)^{2}} \geq 0,
$$

where $m$ is the number of observations in each object, or in this case, the total number of grid points in the horizontal plane (248004). A unique $n \times n$ dissimilarity matrix $\mathbf{E}$, formed by the pairwise Euclidean distances, is computed for each 5-min model output time during the storm's life cycle (2130-0300 UTC, or $64 \Delta t$ ). Each matrix $\mathbf{E}$ is normalized to form a new normalized distance matrix $\mathbf{D}$, whose elements are computed as

$$
0 \leq d_{i j}=\frac{e_{i j}-e_{\min }}{e_{\max }-e_{\min }} \leq 1,
$$

where $e_{\min }$ and $e_{\max }$ are the minimum and maximum distances, respectively, of the original distance matrix $\mathbf{E}$. All unique normalized matrix elements $d_{i j}$ are averaged over all times, and the resulting matrix $\overline{\mathbf{D}}$ is then used as a composite distance measure in HCA using Ward's algorithm (Ward 1963; Murtagh and Legendre 2014). This procedure is similar to that used by Johnson et al. (2011a) to perform HCA on ensemble precipitation forecasts.

The results of hierarchical clustering are displayed graphically as a dendrogram, which shows a stepwise merging of the various clusters identified by the algorithm. Each simulation is initially a single-member group displayed along the bottom. Each single-element group is then merged with the next most similar member. The vertical height of each merger, represented by a horizontal line connecting the two groups, indicates the increase in within-group variance caused by the combination. This process of merging the most similar groups is repeated until all groups are combined. Thus, lower-level clusters are composed of simulation members that are more similar to each other than those merged near the top.

Once meaningful groups of ensemble members are computed using HCA, we quantify differences between groups and CTRLE members to investigate group differences. For each variable (except storm-total rainfall), the field presented, $\overline{\mathbf{Y}}$, is computed as

$$
\overline{\mathbf{Y}}(x, y)=\frac{1}{\ell} \sum_{c=1}^{\ell} \max _{1 \leq t \leq n t} \mathbf{A}_{c}(x, y, t)-\frac{1}{k} \sum_{d=1}^{k} \max _{1 \leq t \leq n t} \mathbf{B}_{d}(x, y, t),
$$

where $\mathbf{A}_{c}$ is the $c$ th HCA member in a group with $\ell$ members, $\mathbf{B}_{d}$ is the $d$ th member of either another HCA grouping or CTRLE with $k$ members, and $t$ is time with $n t$ time steps spanning the storm's lifetime. For nearsurface temperature, $\min$ is used in place of max to investigate surface cold pool strength. These fields, $\overline{\mathbf{Y}}$, represent the difference between group-averaged, timemaximum (or minimum, for near-surface temperature) values at each grid point of two HCA groups or one HCA group and CTRLE. Because storm-total rainfall is already a cumulative quantity, the computation for its field is simply a difference between point-to-point group averages of the run-total accumulated rainfall, computed as

$$
\overline{\mathbf{Y}}(x, y)=\frac{1}{\ell} \sum_{c=1}^{\ell} \mathbf{A}_{c}(x, y)-\frac{1}{k} \sum_{d=1}^{k} \mathbf{B}_{d}(x, y) .
$$

To test the significance of group difference fields, permutation tests for the difference of group means (Pitman 1938) are conducted. This nonparametric permutation test assesses the significance of the difference between the means of two samples (groups) without any assumptions about the distributions of the sampled population. The significance of the test statistic $p$ represents the probability that the difference between the means of the two groups could arise by pure chance. In each analysis, 10000 permutations are performed, and results are analyzed for significance at $p=5.0 \%$.

\section{Event description and CTRL results}

On the afternoon of 31 May 2013, surface-based CAPE (SBCAPE) in excess of $4000 \mathrm{~J} \mathrm{~kg}^{-1}$, negligible surface-based CIN (SBCIN), effective bulk shear from 50 to $60 \mathrm{kt}\left(1 \mathrm{kt}=0.5144 \mathrm{~m} \mathrm{~s}^{-1}\right)$, and $0-1-$ and $0-3-\mathrm{km}$ storm-relative helicity values of approximately 100 and $200 \mathrm{~m}^{2} \mathrm{~s}^{-2}$, respectively, characterized the unstable warm sector over central Oklahoma, east of a surface trough in western Oklahoma and south of a stationary 

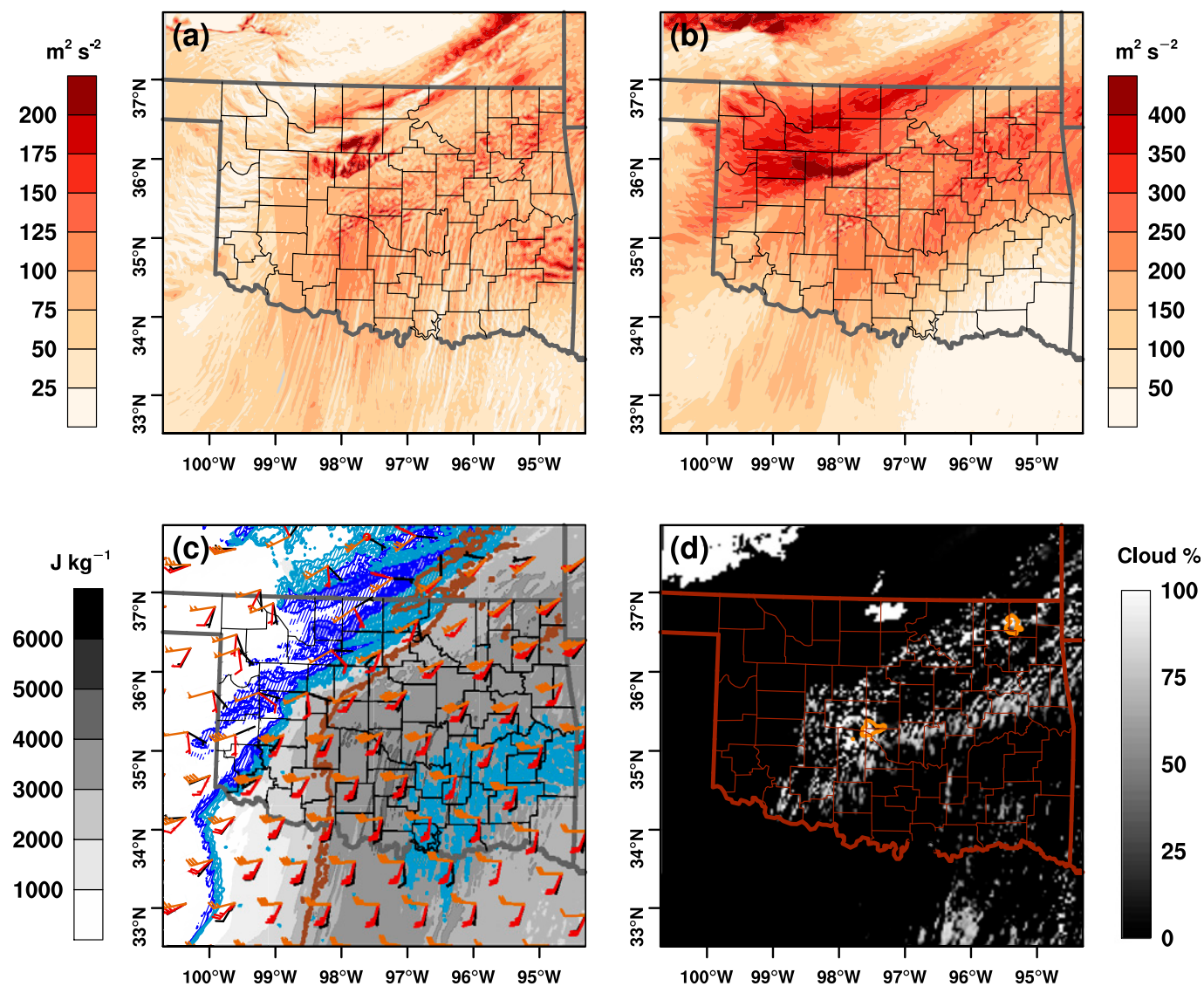

FIG. 2. (a) Color-filled contours of 0-1-km SRH $\left(\mathrm{m}^{2} \mathrm{~s}^{-2}\right)$ at 2100 UTC 31 May 2013 for d02 of CTRL. State and county boundaries are outlined in gray for reference. (b) As in (a), but for 0-3-km SRH. (c) Mesoscale conditions at 2100 UTC 31 May 2013, just prior to convective initiation, taken from d02 of the CTRL run. SBCAPE ( $\left.\mathrm{Jg}^{-1}\right)$ is shaded in grayscale. SBCIN $\left(\mathrm{J} \mathrm{kg}^{-1}\right)$ is contoured and hatched every $25 \mathrm{~J} \mathrm{~kg}^{-1}$ in light blue for $25-100 \mathrm{~J} \mathrm{~kg}^{-1}$ and in dark blue above that. Additionally, 10-m (black), 850-hPa (red), and 500-hPa (orange) wind barbs (kt) are plotted. The $20^{\circ} \mathrm{C}$ dewpoint temperature line is contoured in brown as an approximation for location of the dryline and stationary front. (d) Shaded contours of maximum cloud coverage (\%) in the lowest $5 \mathrm{~km}$ and contours of $35 \mathrm{dBZ}$ at $-10^{\circ} \mathrm{C}$ in orange. State and county boundaries are outlined in red for reference.

front draping across northwestern Oklahoma. In other words, all of the ingredients for severe convection (e.g., Johns and Doswell 1992) were present. Conditions within the CTRL simulation's warm sector (Figs. 2a-c) generally agree with these observations. Thus, it is no surprise that the model initiates convection over central Oklahoma near the intersection of the dryline and stationary front (Fig. 2c) at approximately 2200 UTC. From here on, because land-use conditions have been modified, textual discussion of model results relative to actual geographic locations within the domain will be omitted in favor of domain-relative references.

In d02 of CTRL, simulated convection near this "triple point" intersection in the center of the domain (Fig. 3a) moves eastward off the boundary, and evolves into a long-lived supercell (Figs. 3b,c). The simulated supercell produces a midlevel mesocyclone with $\zeta_{\max } \geq 0.02 \mathrm{~s}^{-1}$ from 2210 to 0300 UTC as it moves nearly due eastward at $\sim 8 \mathrm{~m} \mathrm{~s}^{-1}$. Eventually, this initial supercell dissipates around 0330 UTC, followed by a new area of convection to the north of the supercell (Fig. 3d). This convective system organizes into a line of training precipitation cells (Chappell 1986; Figs. 3d,e), which remains stationary over the eastern part of the domain through the end of the model run. This system of training precipitation and the initial supercell results in over $150 \mathrm{~mm}$ of rain in some locations (Fig. 3f). This simulated convective evolution is similar to reality, though it occurs too far east and convective coverage is sparser. However, these discrepancies are not germane to the current study, given that the present goal is to simulate an isolated supercell interacting with different parts of a city, not to reproduce exactly the events of 31 May 2013. The results presented here will focus on the initial isolated supercell (henceforth referred to as S1), 

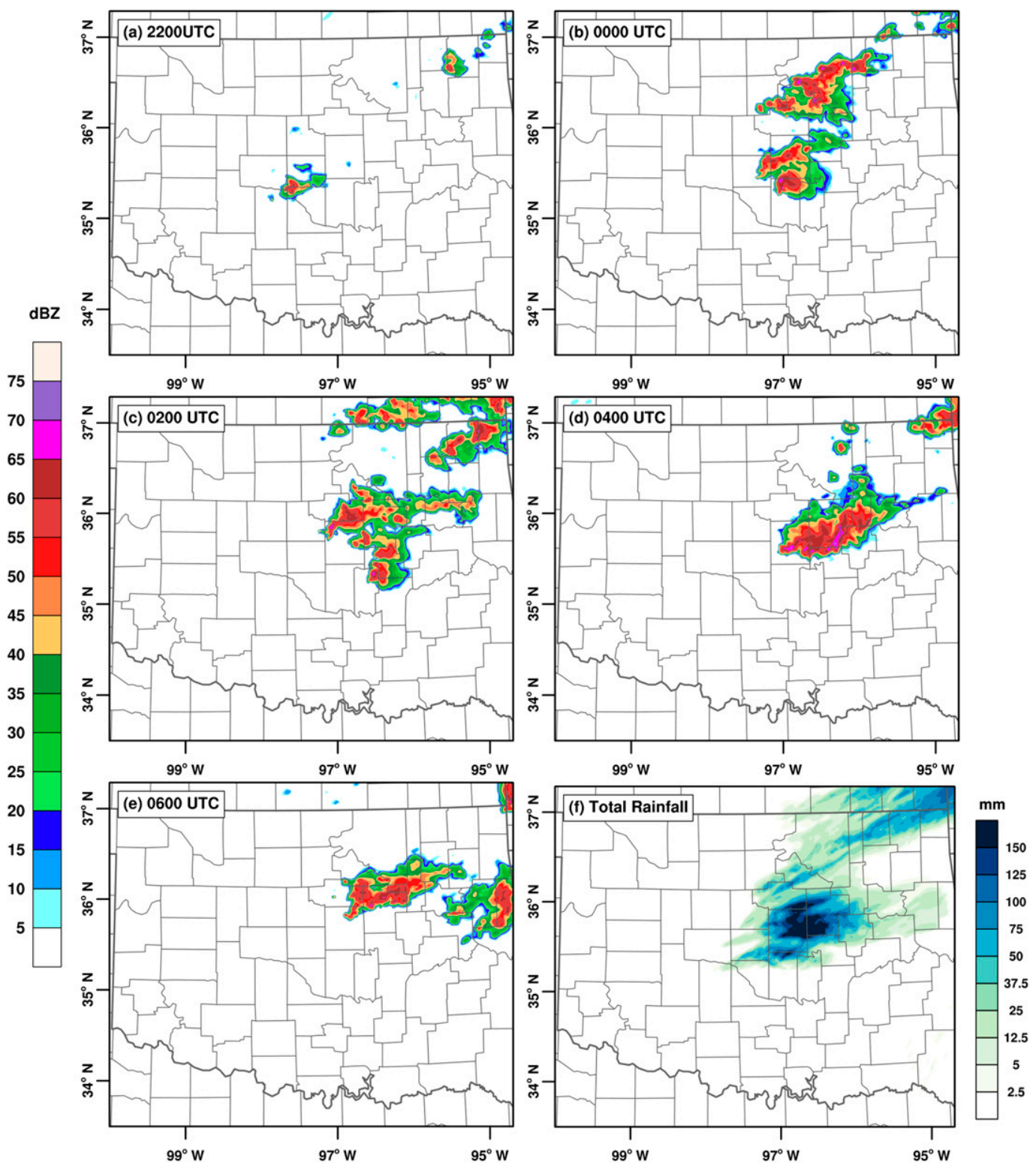

FIG. 3. Color-filled contours of simulated reflectivity (dBZ) at $1 \mathrm{~km}$ AGL from d02 of the CTRL simulation at (a) 2200, (b) 0000, (c) 0200, (d) 0400, and (e) 0600 UTC. (f) Filled contours of d02 CTRL rainfall accumulated from 2100 to 0600 UTC.

from formation at $\sim 2130$ UTC to its demise at $\sim 0300$ UTC. As such, all subsequent simulation details are from d03.

Detailed analysis of d03 simulated reflectivity indicates S1 storm initiation at approximately 2135 UTC (Fig. 4a), and roughly an hour later, a hook echo forms. The hook echo is accompanied by a concentrated region of large values of $2-5-\mathrm{km}$ updraft helicity (UH; e.g., Kain et al. 2008), defined as the vertically integrated product of vertical vorticity $\zeta$ and vertical velocity $w$, which indicates mesocyclone location (Fig. 4b). Also around this time, a cell forms on the north flank of S1. When this new cell moves north and away from S1 around 2300 UTC, the hook echo of S1 becomes more defined, and the area of large UH values expands (Fig. 4c). Around 2345 UTC (Fig. 4d), the S1's mesocyclone begins to cycle, with a new region of rotation forming to its west (S1a). Additionally, a new cell forms just to the west of S1. This flanking cell (henceforth referred to as S2) strengthens and develops a mesocyclone that eventually overtakes $\mathrm{S} 1$, thus becoming the dominant mesocyclone (Fig. 4e). Approximately an hour 

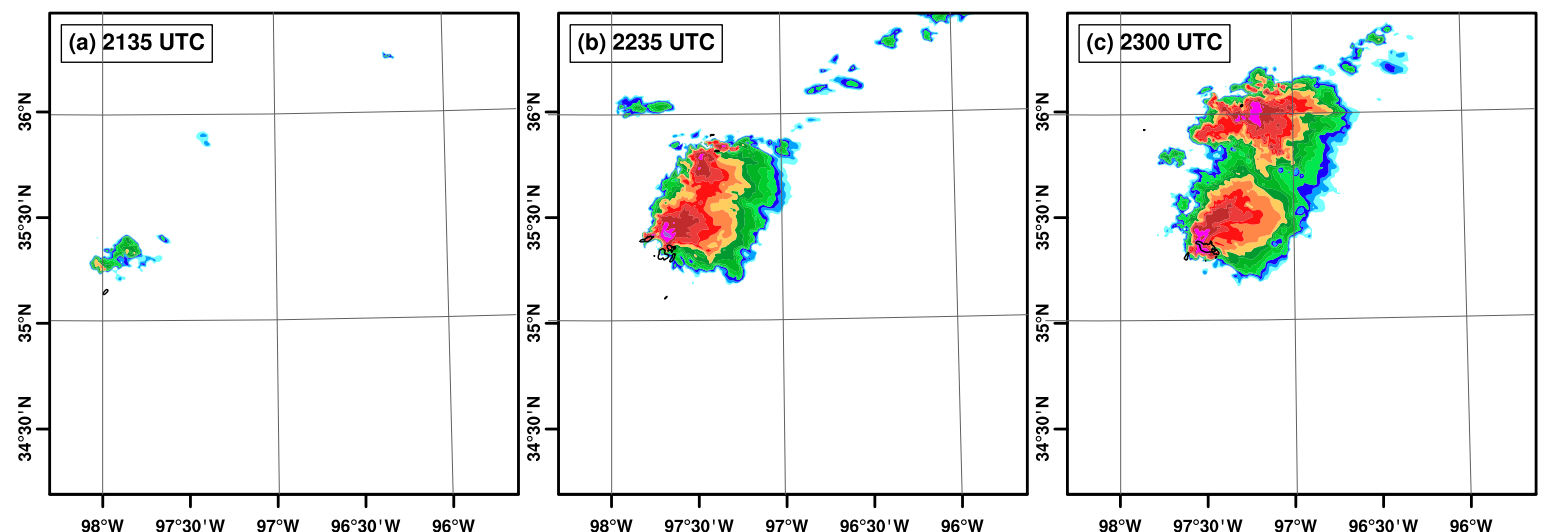

dBZ
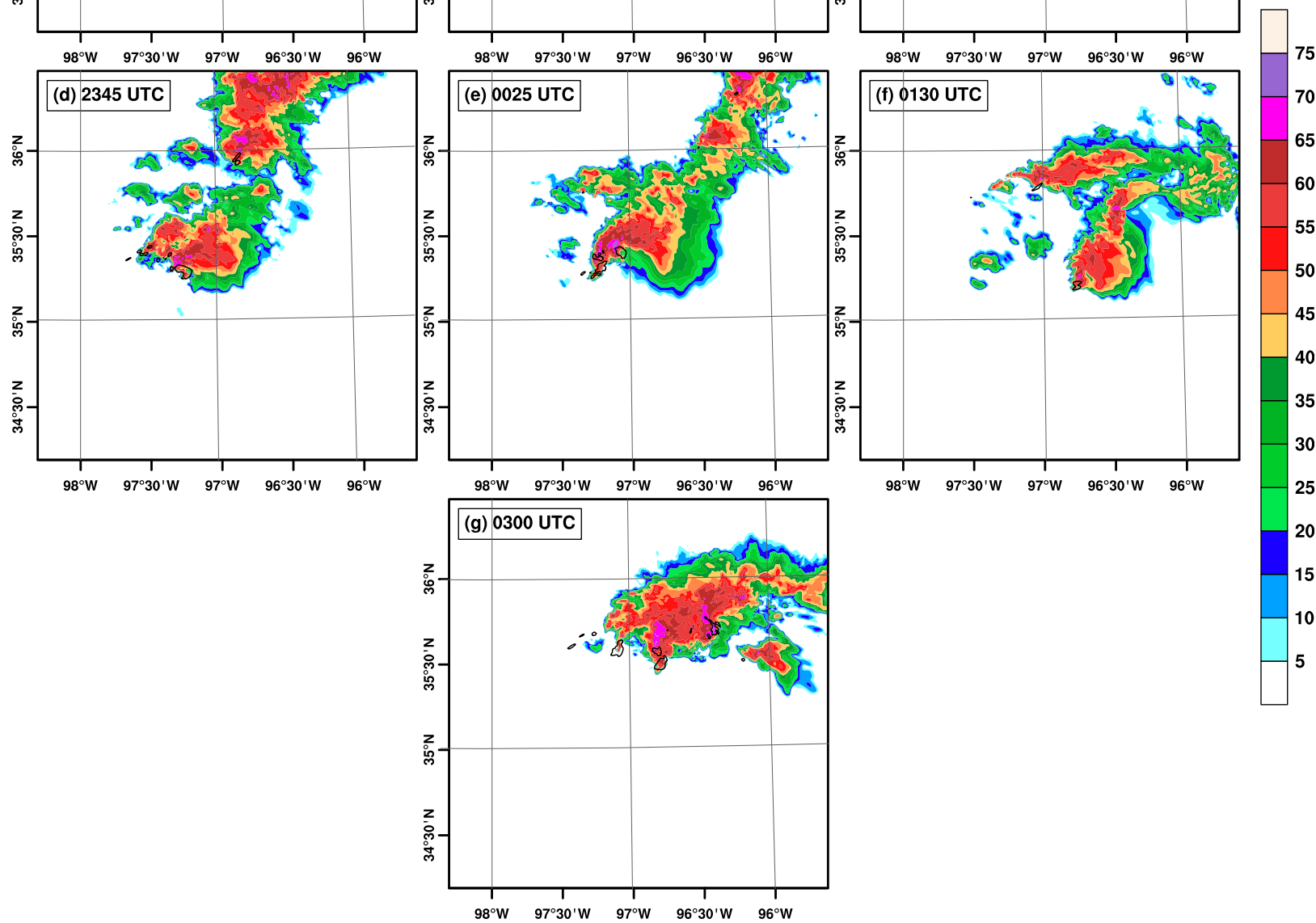

FIG. 4. Color-filled contours of simulated reflectivity (dBZ) at $1 \mathrm{~km} \mathrm{AGL}$ and contours of $800 \mathrm{~m}^{2} \mathrm{~s}^{-2} 2-5-\mathrm{km}$ UH (black) from d03 of the CTRL simulation at (a) 2135, (b) 2235, (c) 2300, (d) 2345, (e) 0025, (f) 0130, and (g) 0300 UTC.

later, the S2 begins to weaken (Fig. 4f), and it is almost completely dissipated by 0300 UTC (Fig. 4g).

The resulting mesocyclone tracks, computed using a 3D object-tracking algorithm similar to that used by Clark et al. (2012), depict a complicated evolution as S1 moves eastward, cycles (resulting in S1a), and then is overcome by S2 (Fig. 5), whose mesocyclone track starts southwest of S1's track termination and continues on with a similar eastward motion. Although the two shorter, more northern tracks (the longest of which is associated with S1a) occurred during the same general time frame as those of
S1 and S2, times are only marked on the southernmost tracks. Near-surface wind speeds (Fig. 5a) are strongest near S1's track, with speeds exceeding $35 \mathrm{~m} \mathrm{~s}^{-1}$ in some locations. However, 2-5-km UH remains high for much longer (Fig. 5d), until S2 weakens and takes a more northerly track, beginning just after 0100 UTC. Rainfall is mainly concentrated north of the S1's track (Fig. 5c), as are the cooler near-surface temperatures accompanying the rain-cooled downdraft (Fig. 5b).

Time series of mesocyclone-averaged $0-1$ - and 2-5-km updraft helicity (Fig. 6b) suggest that midlevel 

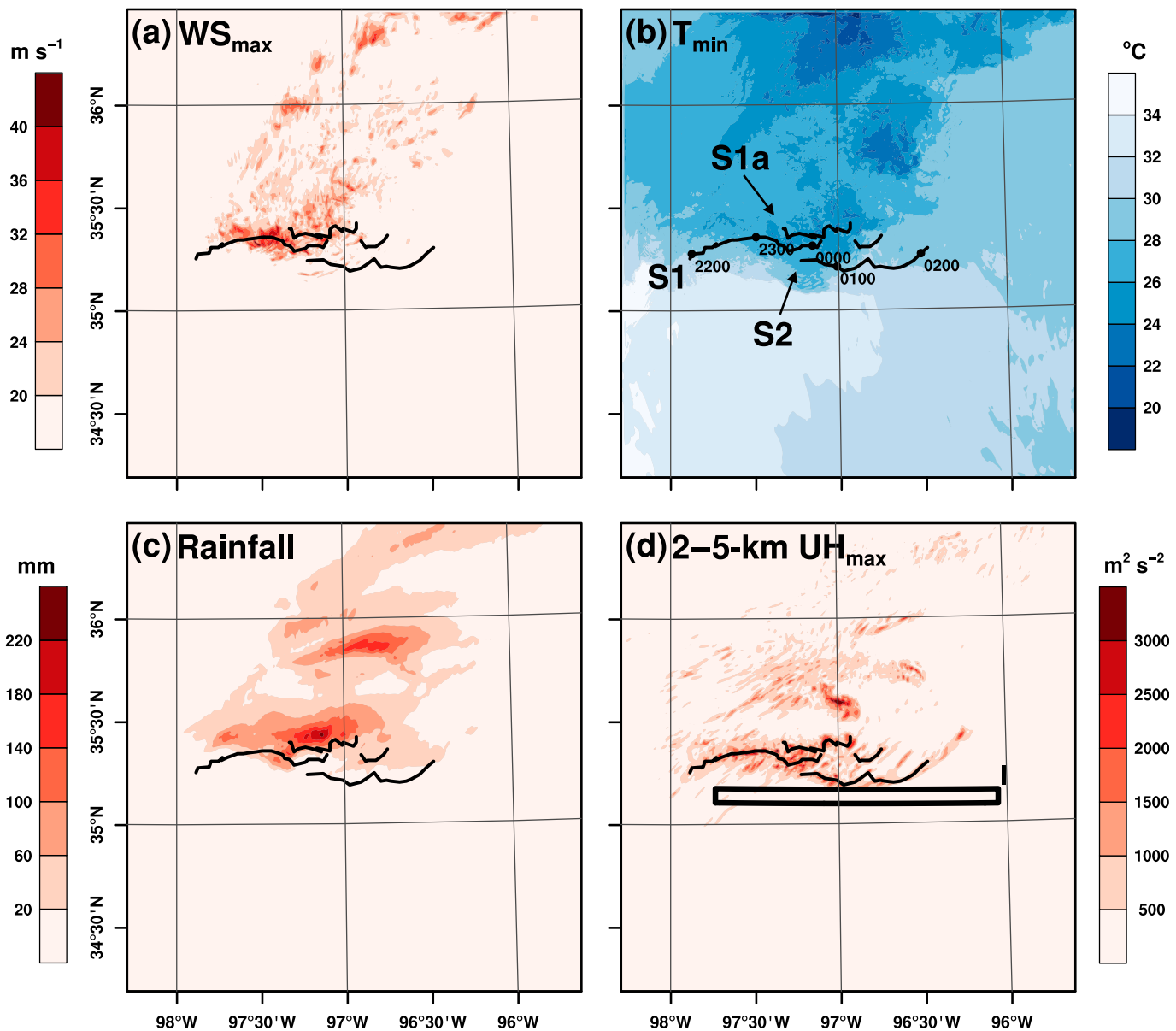

FIG. 5. Color-filled contours of CTRL d03 entire simulation time composite (a) maximum near-surface (first model level, $\sim 25 \mathrm{~m}$ ) wind speed, (b) minimum near-surface temperature, (c) total rainfall, and (d) maximum 2-5-km UH. Mesocyclone track lines are in black, and the names and locations of the mesocyclones at every hour (UTC) are noted in (b) with dots and time labels. Inflow characteristics in Figs. 17 and 18 are computed over box I in (d).

mesocyclone strength is greatest from 0000 to 0130 UTC, as indicated by plateaus of $3-\mathrm{km} \zeta_{\text {avg }}$ and $2-5-\mathrm{km}$ $\mathrm{UH}$ at $\sim 0.02 \mathrm{~s}^{-1}$ and $\sim 4000 \mathrm{~m}^{2} \mathrm{~s}^{-2}$, respectively. While first-model-level $\zeta_{\text {avg }}$ is also elevated over this time, lowlevel mesocyclone strength, as determined by $0-1-\mathrm{km} \mathrm{UH}$, is only relatively strong from $\sim 0000$ to $0030 \mathrm{UTC}$, which is just after the beginning S2's mesocyclone track. These decreased $0-1-\mathrm{km}$ UH values, along with weaker nearsurface wind speeds and warmer near-surface temperatures associated with S2's track, suggest that S2 is weaker in the low levels than $\mathrm{S} 1$ in the CTRL simulation.

\section{Urban simulation results}

\section{a. Prestorm urban environment}

It is important to establish that the model is producing reasonable urban area-atmosphere interactions before attributing any differences in storm strength and evolution among the 108 different urban runs to urban effects. To investigate simulated properties of the urban area, mean differences are shown between simulation x240.y183 (Figs. 1c,d) and CTRL in the hour prior to storm initiation (2030-2130 UTC; Fig. 7). While the magnitudes of these urban effects are not identical across all urban simulation members, the general nature of the changes remains consistent; hence, prestorm urban effects are only shown from this simulation.

The urban boundary layer is generally warmer (Fig. 7a) and drier (Fig. 7b) near the surface than CTRL, consistent with UHI theory and the replacement of natural with nonporous urban surfaces (e.g., Barlow 2014). This warm, dry air also is advected downwind (north and east) of the city. The rough urban surface begets wind speeds that are at least $1.5 \mathrm{~m} \mathrm{~s}^{-1}$ slower than in the CTRL run (Fig. $7 \mathrm{c}$ ), or an approximate $20 \%$ reduction from rural winds, over and downwind of the city. 
(a)
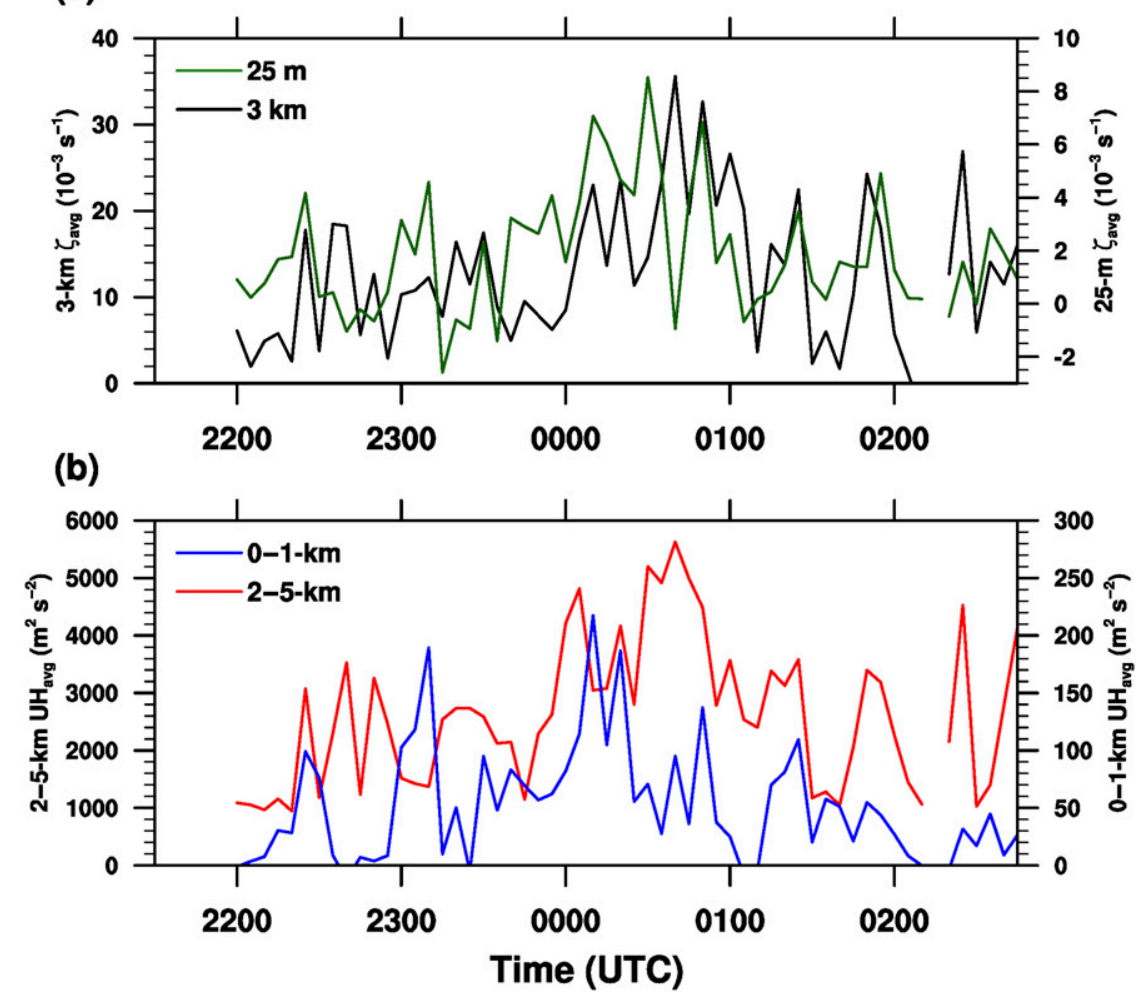

FIG. 6. CTRL variables averaged over mesocyclone area as a function of time. (a) Vertical vorticity $\zeta$ at $25 \mathrm{~m}$ and $3 \mathrm{~km}$ AGL, in black and green and plotted against the right and left axes, respectively. (b) 2-5- and 0-1-km UH in red and blue and plotted against the left and right axes, respectively.

Wind speed decreases of this magnitude over urban areas have been observed and simulated by previous studies (e.g., Hu et al. 2016; RS17). Winds generally veer in the wake of the city (Fig. $7 \mathrm{~d}$ ) by $10^{\circ}-15^{\circ}$; however, a narrow band of backed winds exists downwind of the eastern edge of the city. The slower, convergent winds in the wake of the city are evidence of a building-barrier effect (Bornstein and Lin 2000), whereby winds converge downwind of a city. As a consequence of slower nearsurface winds, $0-1$ - and $0-3-\mathrm{km}$ SRH are $\sim 40-60 \mathrm{~m}^{2} \mathrm{~s}^{-2}$ higher in the vicinity of the urban area, increases of $\sim 50 \%$ and $\sim 25 \%$, respectively (Figs. 7 e,f). However, veered winds north of the urban area result in small decreases in $0-1-\mathrm{km}$ SRH downwind of the city. As these results are generally consistent with theory and observations, we can be confident that the model is simulating reasonable urban-atmosphere interactions.

\section{b. HCA of DFW simulations}

We will examine the clusters that result from performing HCA on various parameters as a function of the geographic location of the urban area in each simulation member. Using clusters whose members have widespread city locations results in little insight about the effects of city location relative to the storm, making any results derived from such HCA groupings uninterpretable. Hence, we seek HCA results of some parameter that provide clusters whose member city locations are similarly located, indicating a dependence of that variable on city location.

Generally, the members in each group resulting from performing HCA on 2-5-km UH (Fig. 8) do not have city locations that are geographically collocated. Likewise, member city locations are similarly scattered in the HCA results for rainfall (Fig. 9). These findings suggest that city location is not the primary reason for member differences in $2-5-\mathrm{km} \mathrm{UH}$ and storm-total rainfall. In contrast, the HCA results for 0-1-km UH (Fig. 10), and near-surface wind speed (Fig. 11) and temperature (Fig. 12) suggest that differences in low-level storm characteristics are more dependent on city location. At the highest grouping (i.e., groups with the greatest within-group variance), members with city centers south of and directly under the storm path (i.e., groups $2-7$ in Fig. 10) are grouped separately from those with centers north of the storm path (i.e., group 1 in Fig. 10). Below that, each group generally bifurcates into eastern and 

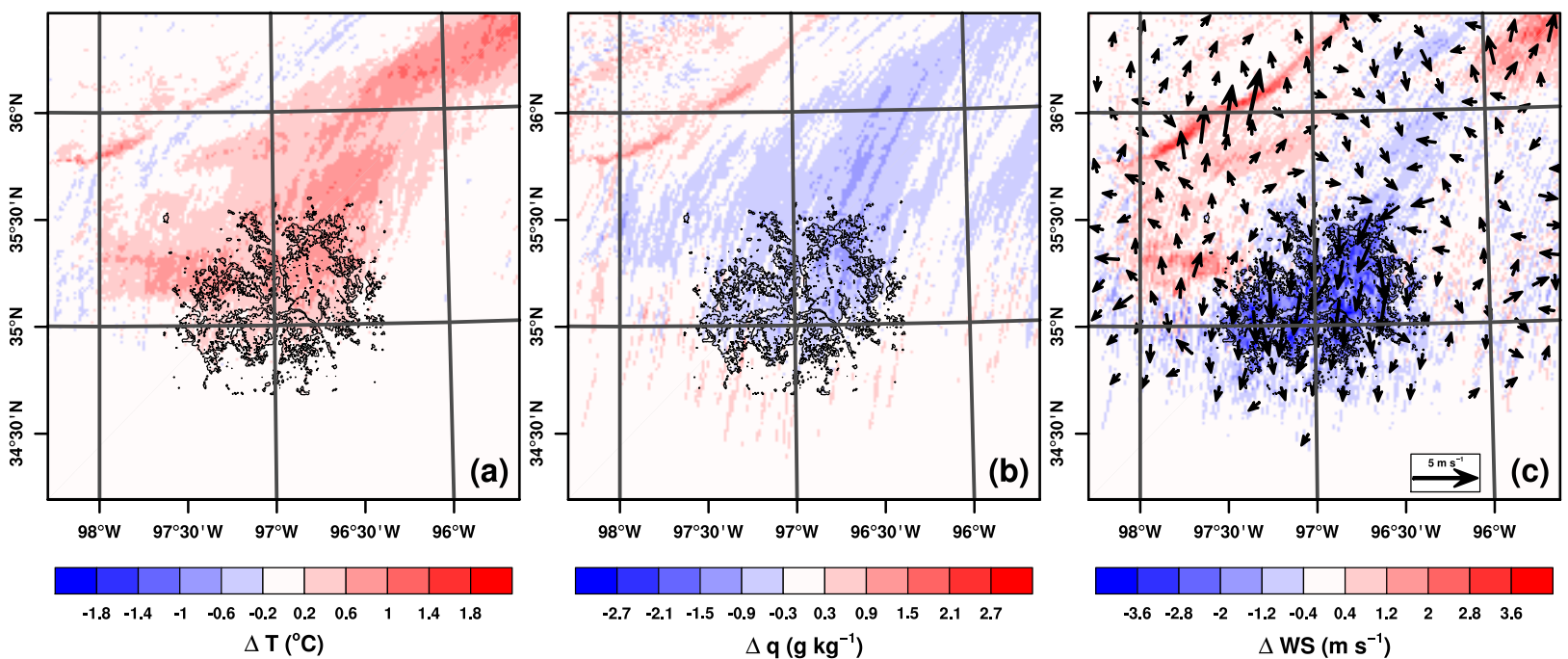

$\begin{array}{llllllllll}-2.7 & -2.1 & -1.5 & -0.9 & -0.3 & 0.3 & 0.9 & 1.5 & 2.1 & 2.7\end{array}$

$\Delta \mathbf{q}\left(\mathbf{g ~ k g}^{-1}\right)$
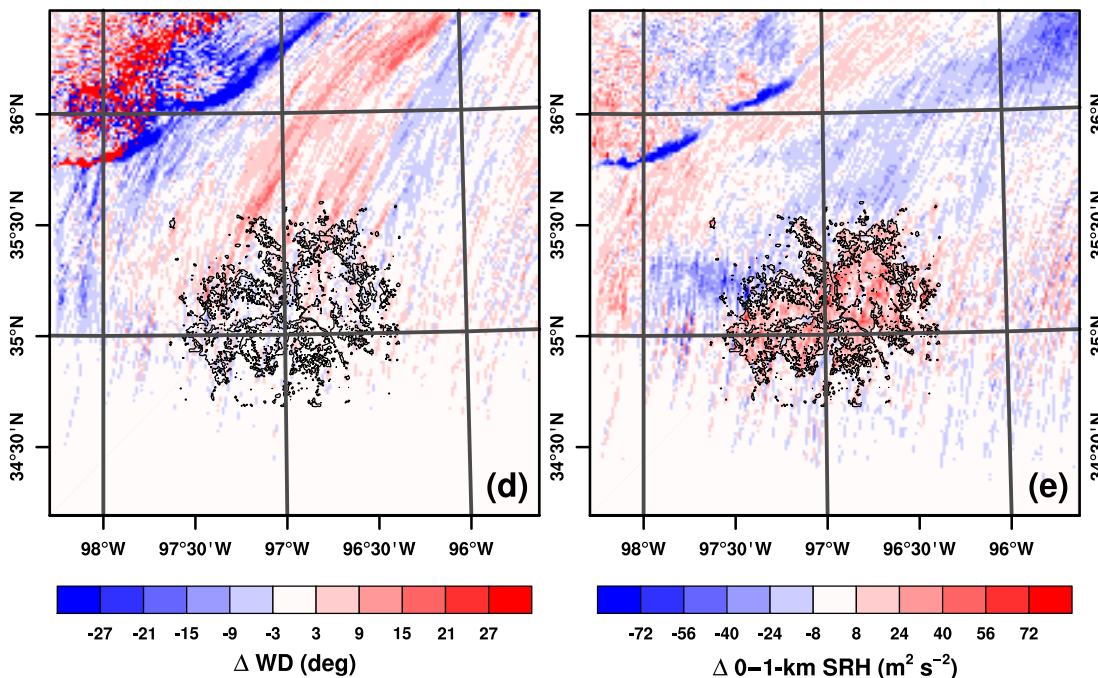

$\begin{array}{llllllllll}-3.6 & -2.8 & -2 & -1.2 & -0.4 & 0.4 & 1.2 & 2 & 2.8 & 3.6\end{array}$ $\Delta \mathrm{WS}\left(\mathrm{m} \mathrm{s}^{-1}\right)$

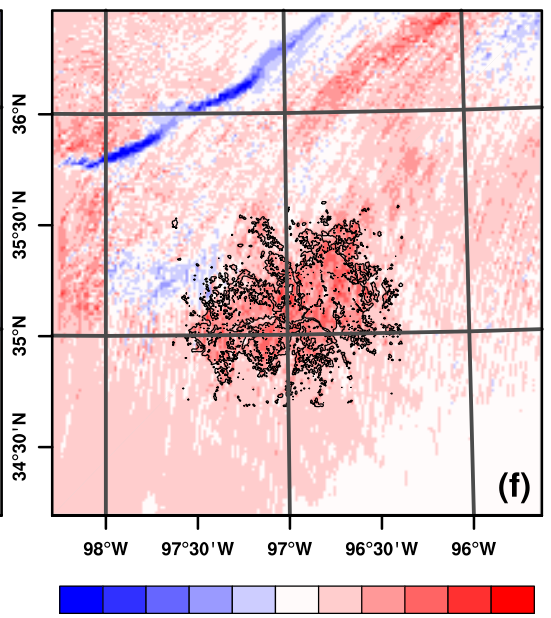

$\begin{array}{llllllllll}-108 & -84 & -60 & -36 & -12 & 12 & 36 & 60 & 84 & 108\end{array}$ $\Delta$ 0-3-km SRH $\left(\mathrm{m}^{2} \mathrm{~s}^{-2}\right)$

FIG. 7. Color-filled contours of the 2030-2130 UTC average difference from CTRL of x240.y210 (a) first-model-level temperature $\left({ }^{\circ} \mathrm{C}\right)$, (b) first-model-level mixing ratio $q\left(\mathrm{~g} \mathrm{~kg}^{-1}\right)$, (c) first model-level wind speed $\left(\mathrm{m} \mathrm{s}^{-1}\right)$, (d) first-model-level wind direction $\left({ }^{\circ}\right)$, (e) 0-1-km SRH $\left(\mathrm{m}^{2} \mathrm{~s}^{-2}\right)$, and (f) 0-3-km SRH. Average vector wind differences over this time period are also plotted in black in (c). Urban fraction of 0.1 is contoured in a thick black line.

western groups (i.e., groups $2-3$ and $4-7$ in Fig. 10), followed by another set of north-south and (in some cases) east-west splits. The members group first (i.e., the bottom-most groups) by east-west city location and then subsequently by north-south location, suggesting that members with similar east-west locations are generally more alike than those with similar north-south locations.

While the HCA groupings for $0-1-\mathrm{km} \mathrm{UH}$, nearsurface wind speed, and near-surface temperature are generally similar, some noticeable differences do exist. For example, in the $0-1-\mathrm{km}$ UH groupings, simulations with city locations in the northern third of the domain (group 1 in Fig. 10) are quite different from those in the southern two-thirds of the domain (groups 2-7), as indicated by the large increase in within-group variance $(>0.25)$ when group 1 is combined with the rest. A similarly large increase in variance $(\approx 0.5)$ occurs when the group of northern city locations from the low-level wind speed HCA (group 6 in Fig. 11) is combined with simulations with city locations in the middle third of the domain (groups 7 and 8). However, variance increases by an even larger amount when groups $6-8$ are combined with $3-5(\approx 0.75)$. This difference between $0-1-\mathrm{km}$ $\mathrm{UH}$ and near-surface wind speed HCA grouping structures indicates that while the final groups may differ little, the order of similarity between the groups can change. The main reason for these differences is that near-surface temperature and wind speeds are modified 

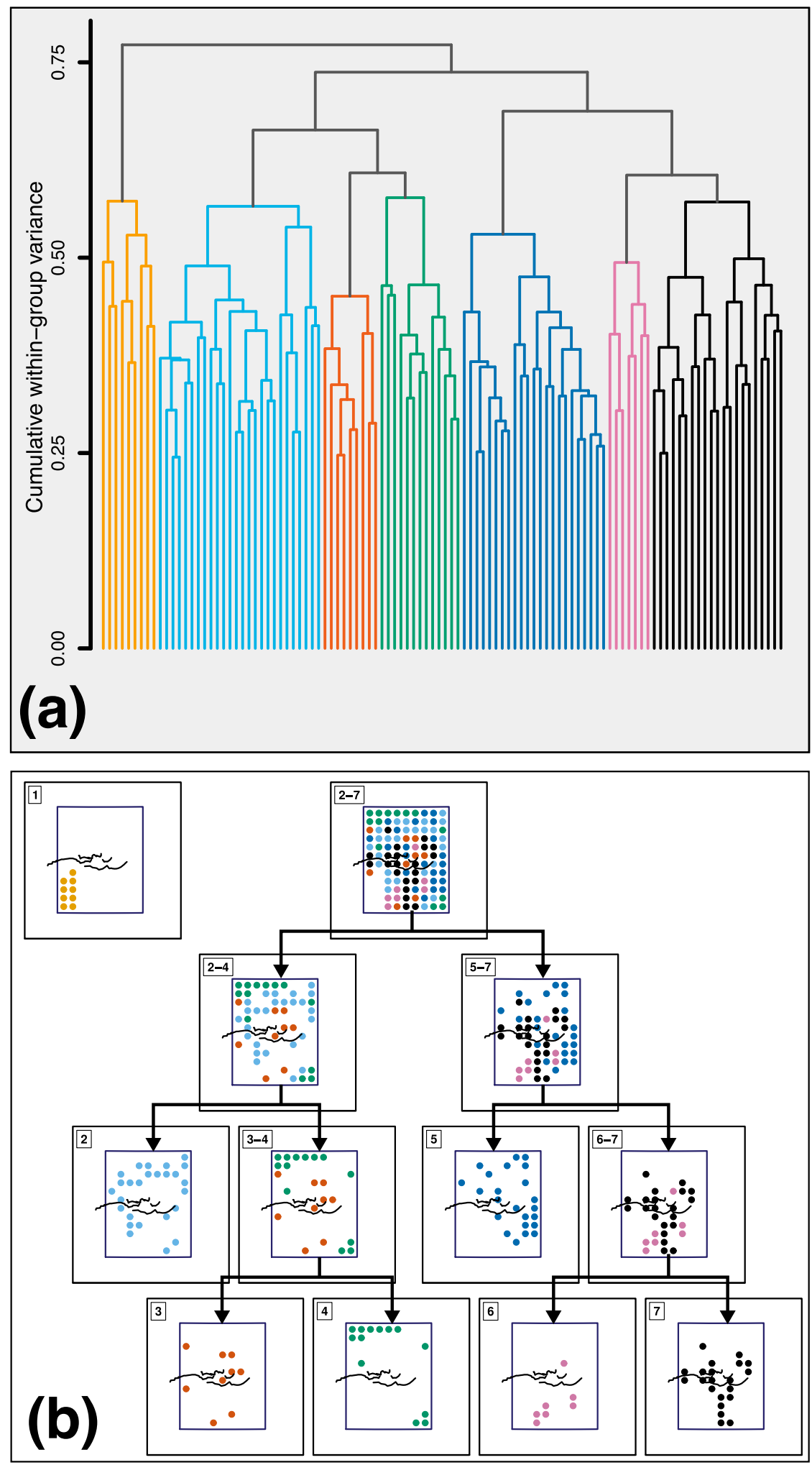

FIG. 8. (a) Dendrogram of 2-5-km UH HCA results and (b) the resulting city-center locations by group. Oklahoma county boundaries are outlined in gray. Colored dendrogram groups in (a) correspond to similarly colored dots in (b). 

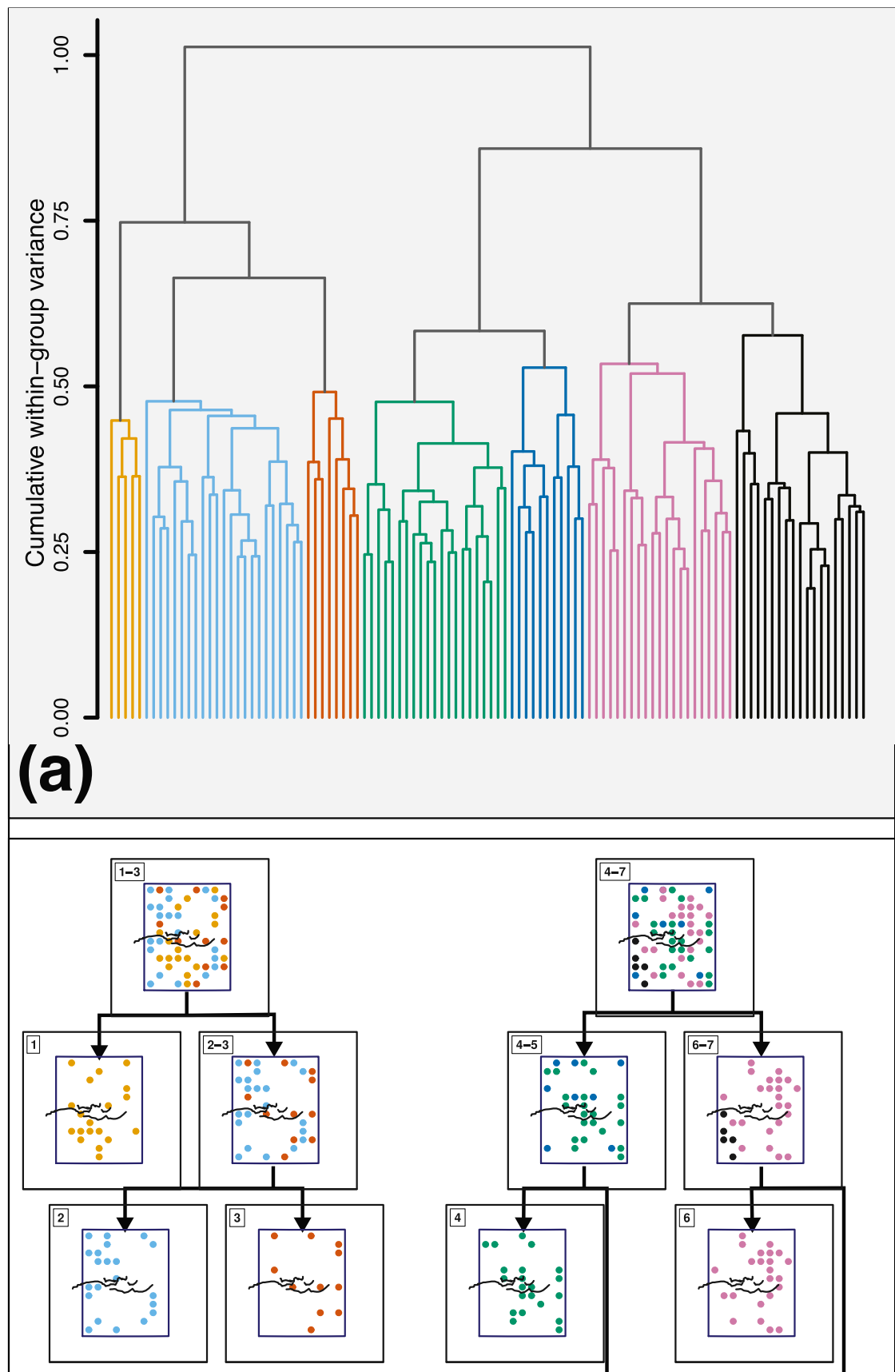

(b)

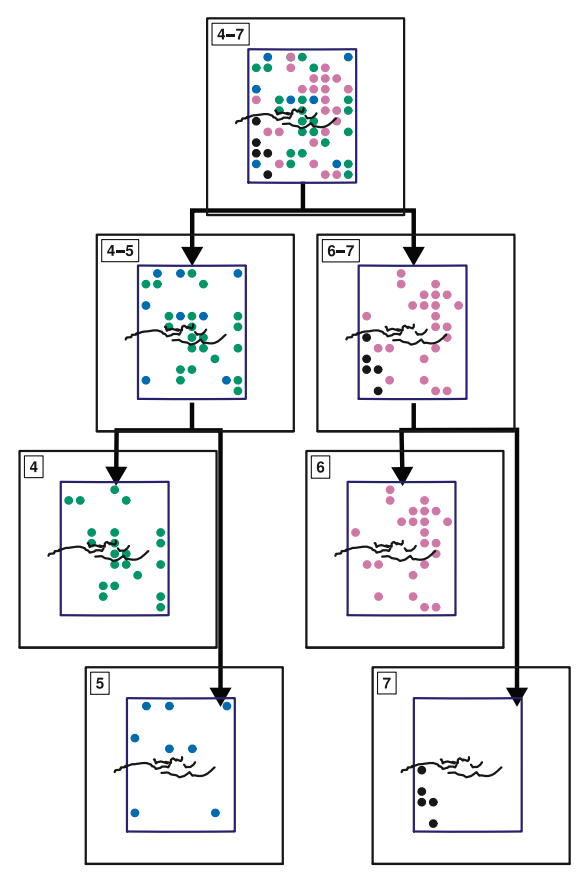

FIG. 9. As in Fig. 8, but for storm-total precipitation. 

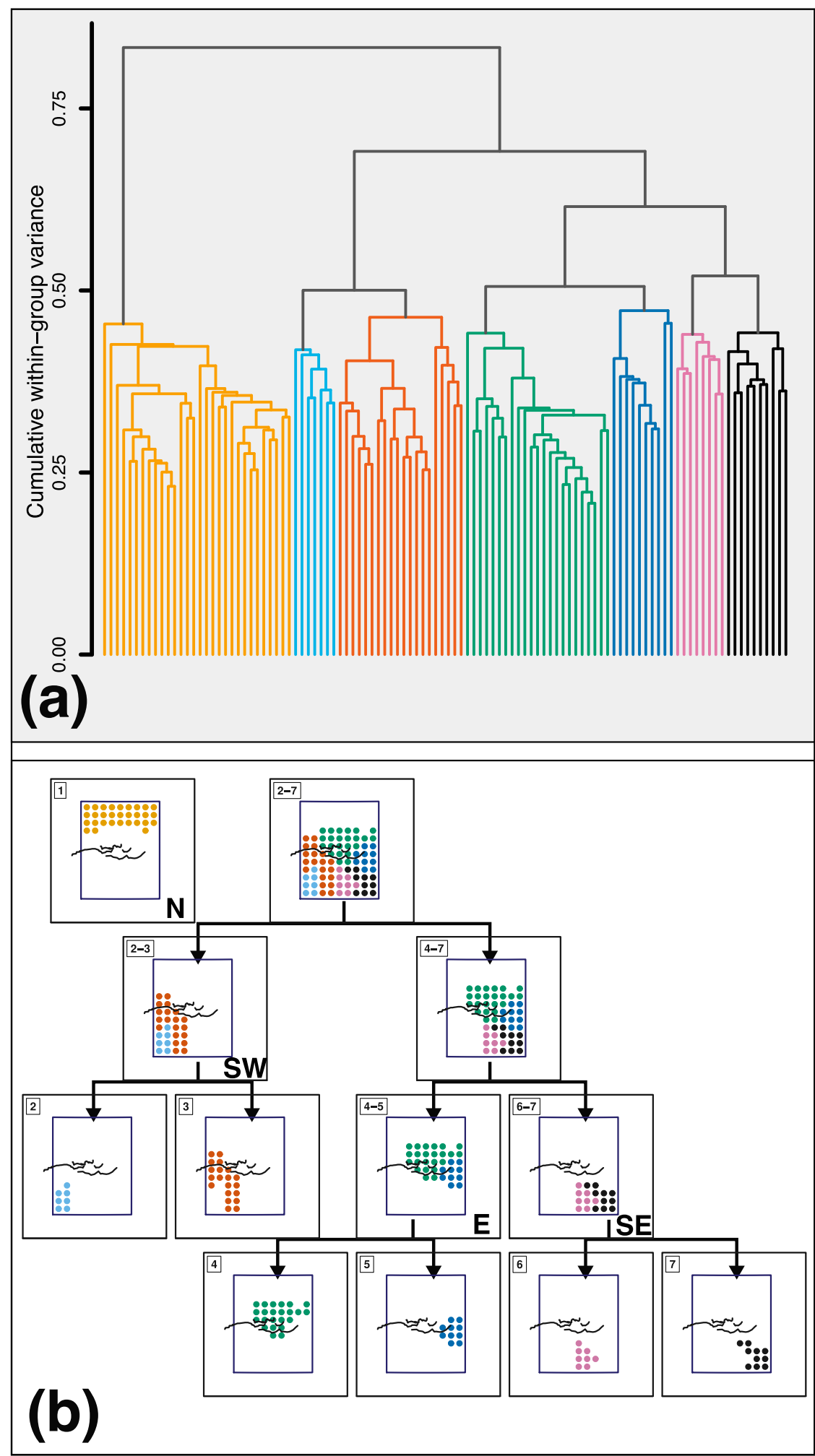

FIG. 10. As in Fig. 8, but for 0-1-km UH. Additionally, names for the groups used in the discussion are labeled. 

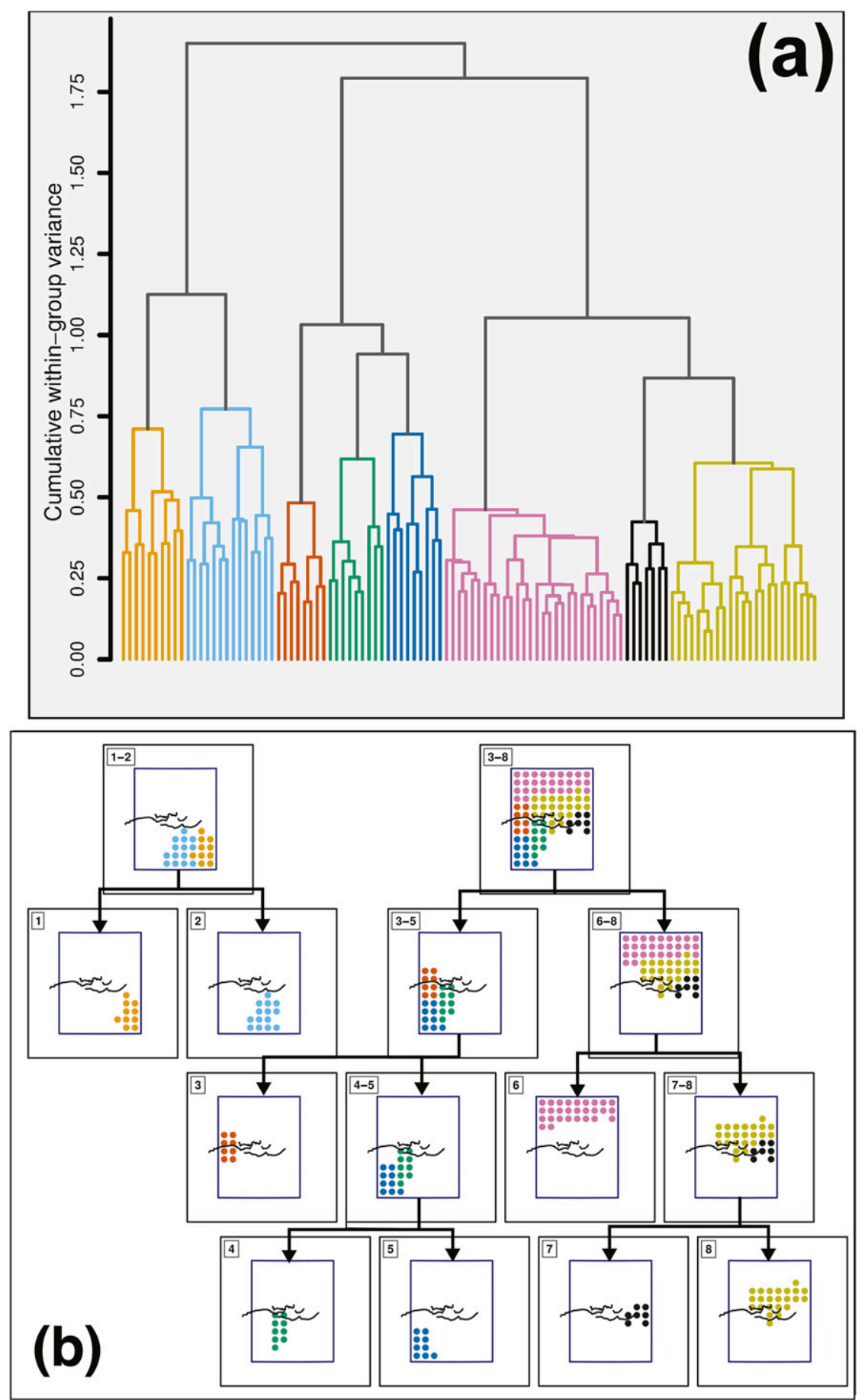

FIG. 11. As in Fig. 8, but for low-level wind speed.

by the urban area before (and regardless of if) the storm interacts with the city. In other words, temperature and wind speed changes are not directly tied to the presence of the storm, but UH is a property of the storm itself and not just the underlying surface. Hence, it is possible that the HCA groupings for near-surface variables are dominated by nonstorm modifications of the nearsurface environment.

To understand how storm characteristics differ across HCA groups, we can examine difference (from CTRLE) fields for several variables that are related to storm strength and evolution. The groupings are 

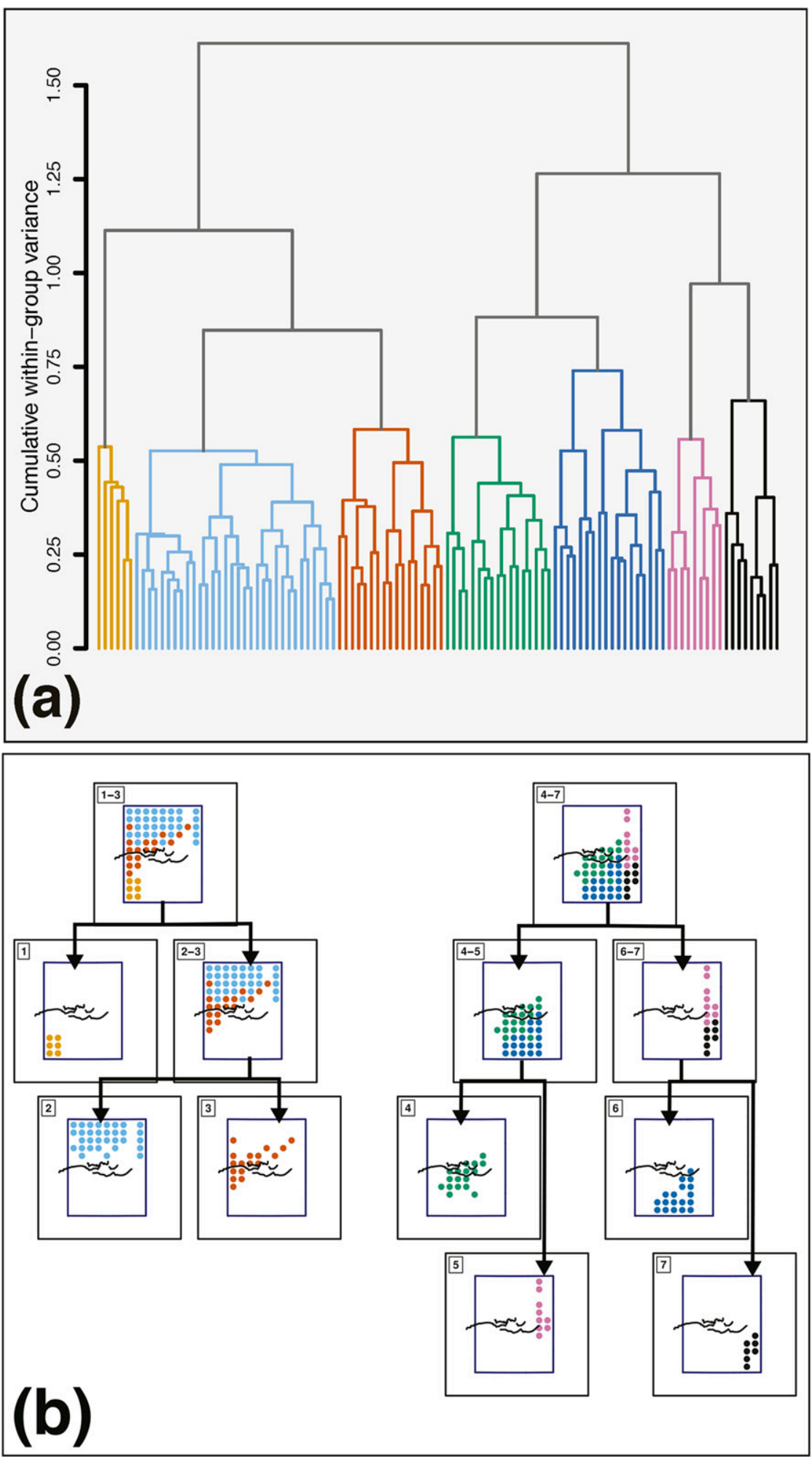

FIG. 12. As in Fig. 8, but for low-level temperature. 


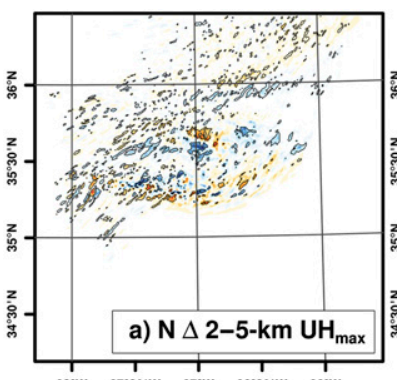

$97^{\circ} 30^{\prime} \mathrm{W} \quad 97^{\circ} \mathrm{W} \quad 96^{\circ} 30^{\prime} \mathrm{W} \quad 96^{\circ} \mathrm{W}$
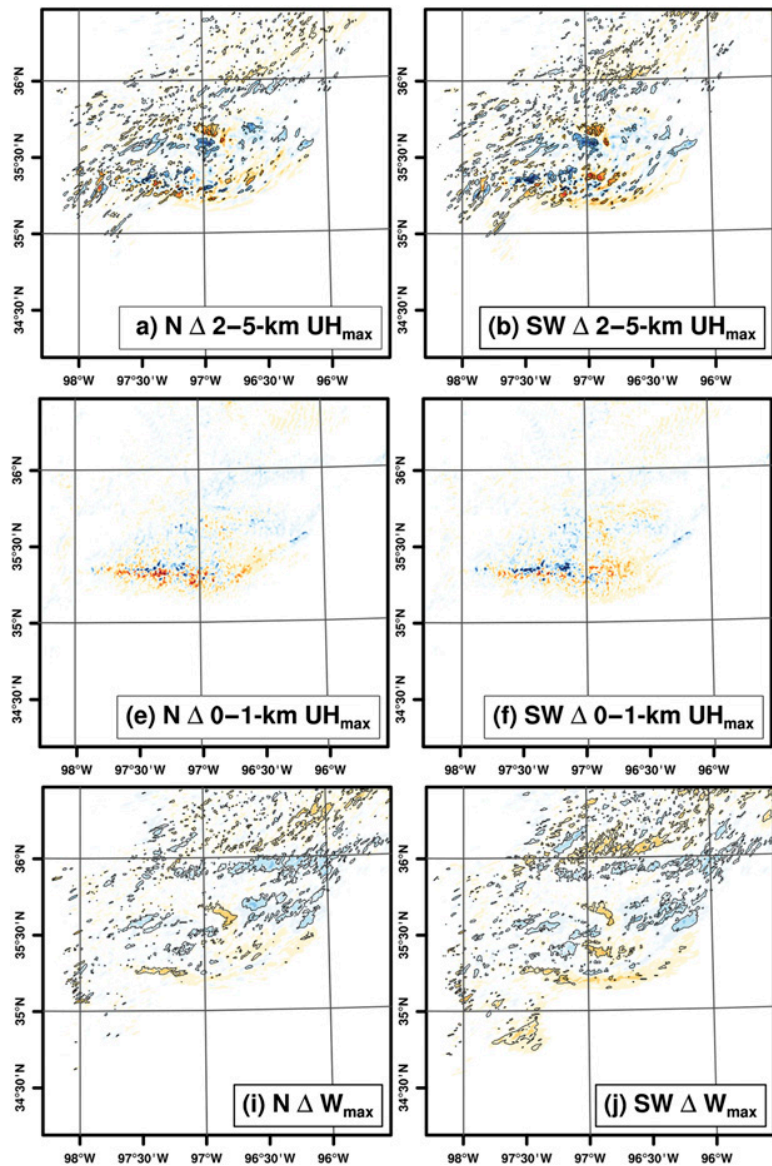

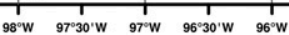
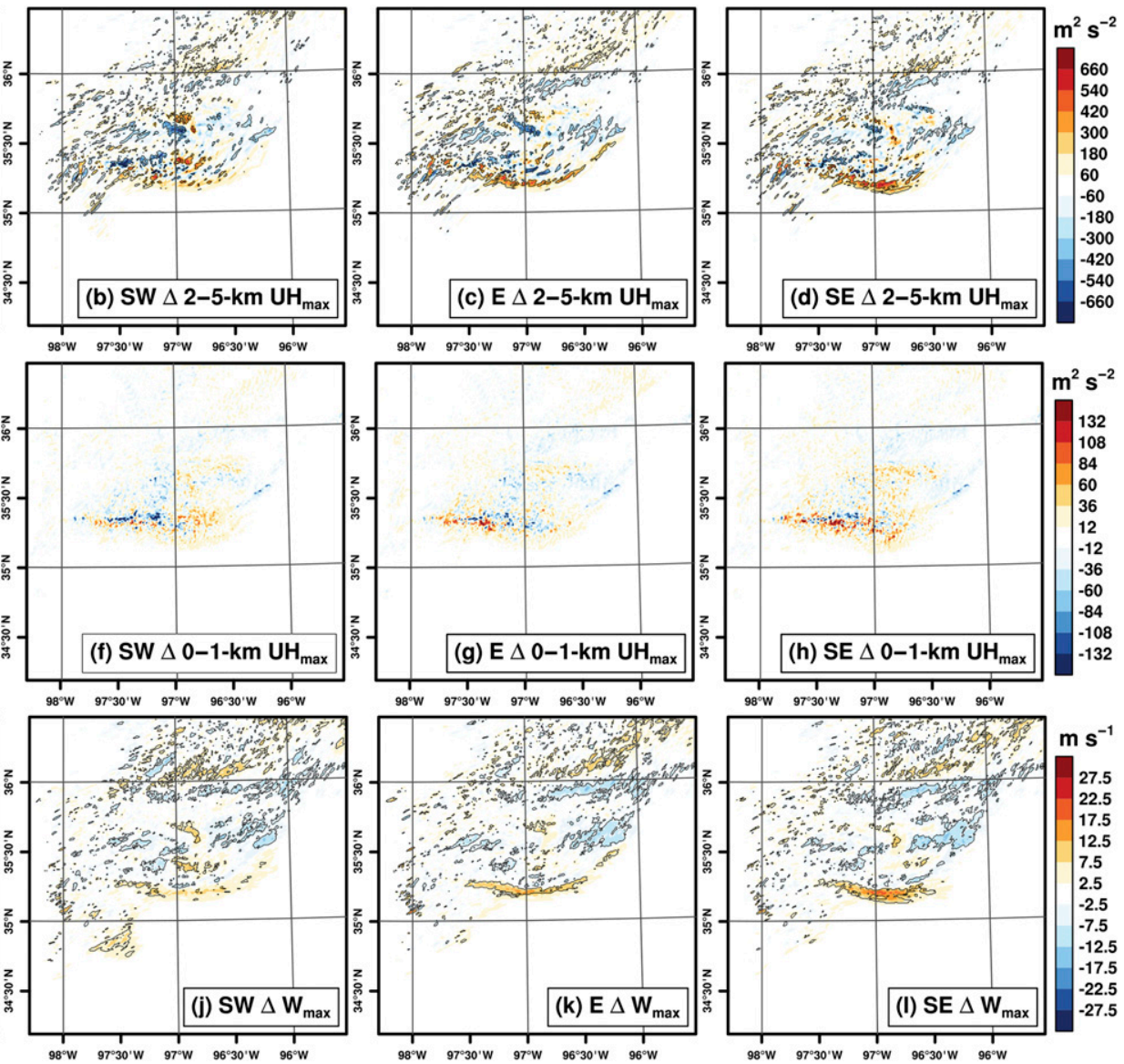

FIG. 13. (a) Color-filled contours of group-averaged differences of group $\mathrm{N}$ from CTRLE in entire simulation time-composite maximum $2-5-\mathrm{km} \mathrm{UH}$. Also, contoured in black are differences that are significant at $\alpha=95 \%$, as computed from permutation testing with 10000 permutations. (b)-(d) As in (a), but for groups SW, E, and SE, respectively. (e)-(h) As in (a)-(d), but for 0-1-km UH. Because of its inconsistent nature, regions of significant differences are not contoured for 0-1-km UH. (i)-(l) As in (a)-(d), but for column-maximum vertical velocity $\left(W_{\max }\right)$.

selected from a single HCA result to simplify interpretation. Since the HCA results of $0-1-\mathrm{km}$ UH, near-surface temperature, and near-surface wind speed each provide grouping structures that are similar, selecting the groups from any of these three variables should provide similar results. Hence, we will analyze difference fields based on the groupings from the $0-1-\mathrm{km}$ UH HCA. Furthermore, to avoid representativeness issues caused by small sample size or large within-group variance, the four groupings with merging heights of $\sim 0.5$ (Fig. 10a) will be examined. These groupings, or groups 1, 2-3, 4-5, and 6-7 in Fig. 10, will be referred to as the north $(\mathrm{N})$, southwest (SW), east (E), and southeast (SE) groups, where the directional names correspond to the general storm-track-relative city location in each group.

Regardless of city location, all simulations with an urban area generally have greater low- and midlevel $\mathrm{UH}$, along with stronger rising motion, than the CTRLE simulations (Fig. 13) along and south of the southernmost mesocyclone track (Fig. 5). This difference is spatially consistent and statistically significant when the city center is in the southeastern and eastern portions of the domain, particularly in the SE group (Figs. 13d,1). Some of these apparent differences in mesocyclone strength can be explained by a more southerly storm track in the SW, E, and SE groups (Fig. 14). Though, if the mesocyclones simply track farther south but are of similar strength, we should in each case see an additional swath of nearly equal magnitude UH change, but of opposite sign, adjacent to the region in question. In the case of both the increased mesocyclone strength of the S2's track for the E and SE groups (Figs. 13c,d,g,h,k,l), as well as the decreased UH near S1 in the SW group (Figs. 13b,f), this kind of pattern is not present. This indicates that the maximum strength of the S2 is indeed increased, and significantly so in the E and SE groups, while the initial mesocyclone is weakened significantly in the SW group. 

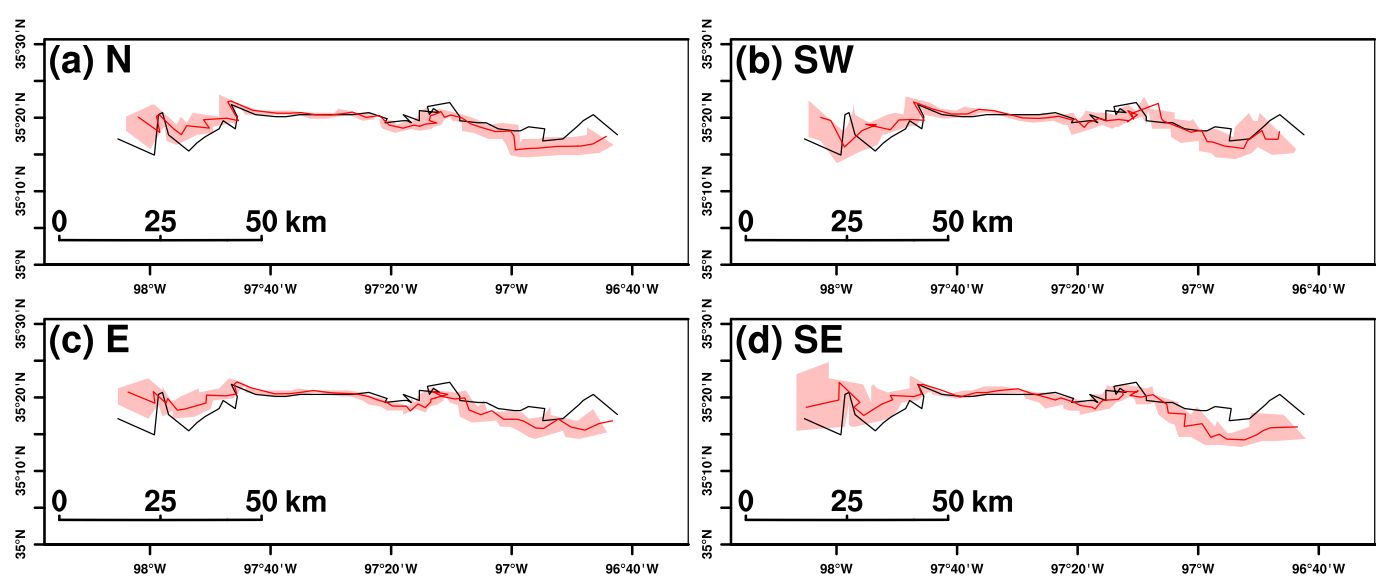

FIG. 14. (a) Location of maximum 2-5-km UH (as a proxy for midlevel mesocyclone location) at each time step, averaged over all CTRLE group members (black line) and over all members of the $\mathrm{N}$ urban group (red line). Pink shading indicates the region encompassing the middle $95 \%$ of bootstrapped urban group mean maximum $2-5-\mathrm{km}$ UH locations. (b)-(d) As in (a), but for urban HCA groups SW, E, and SE.

The most prominent, low-magnitude signals in minimum near-surface temperature (Figs. 15a-d) and maximum near-surface wind speed (Figs. 15e-h) group differences from CTRLE are first-order effects of the urban area. Over and downwind of the general location of the urban area in each group, maximum wind speeds are slower while minimum temperatures are higher, caused by increased friction and the UHI effect, respectively. These effects are particularly evident for the SW (Figs. 15b,f) and SE (Figs. 15d,h) groups, where the city locations are farthest from storm impacts.

Temperature and wind speed differences also are apparent near the storm. All groups have a region of significantly decreased precipitation in the north-central and northeastern portion of the domain. As this region is near the stationary front in the northern portion of the simulation domain, these differences may be associated with a northward shift of the frontal boundary evident in prestorm conditions (Fig. 7). Associated with this decrease in precipitation, run-minimum temperatures are warmer in the northeastern portion of the simulation domain, a change that is most significant for groups N, E, and SE, where the region of decreased precipitation extends farther east. An area of minimum temperatures south of the southern-most mesocyclone track, likely within the storm's rear-flank downdraft (RFD), is over $0.5^{\circ} \mathrm{C}$ cooler than CTRLE for the SW (Fig. 15b) and E (Fig. 15c) groups, while members in the SE group (Fig. 15d) have significantly cooler RFDs, with $T_{\min } \geq 1^{\circ} \mathrm{C}$ cooler than the CTRLE group. Maximum near-surface wind speeds in the vicinity of the storm are generally higher when the storm passes south of the city than in CTRLE (Fig. 15e); however, in groups SW (Fig. 15f) and E (Fig. 15g), urban-induced friction negates these effects over some portions of the storm track. This is not the case, though, for the SE group (Fig. 15h), which experiences stronger near-surface winds over the entire storm track, even when it approaches and traverses the urban area, though this increase is only significant in isolated locations. All urban simulations have areas of significant increase in precipitation (Figs. 15i-1), particularly near the beginning and end of the storm track. The SW group also has a large region of significantly less precipitation near the midpoint of the storm's tracks (Fig. 15).

Evaluating mesocyclone characteristics as a function of time provides insight about timing and strength differences regardless of location within the domain. Here, analysis will be performed using spatially averaged (over the mesocyclone), time-integrated (cumulative) differences from CTRLE; hence, where a time series line has a positive (negative) slope, the mesocyclones in the urban simulations have a higher (lower) average than CTRLE. Cumulative plots of mesocyclone-averaged quantities are preferred, as plotting point-to-point difference as a function of time can be noisy and difficult to interpret. Cumulative group differences from CTRLE in the average of the mesocyclone's top $50 \%$ highest values of 2-5-km UH (Fig. 16a) support the observation from Figs. 13a-d that the all-urban runs have generally higher 2-5-km UH than CTRLE until late in the storm's lifetime, particularly for the SE group. This difference is most evident in the peak for the SW, E, and SE groups before the storm cycles (around 2330 UTC), which is strongest for the SE group. At this time, these differences result in an $\sim 8 \%-10 \%$ increase over CTRLE. However, due to weaker mesocyclones in the urban runs during and after the second mesocyclone forms in the 

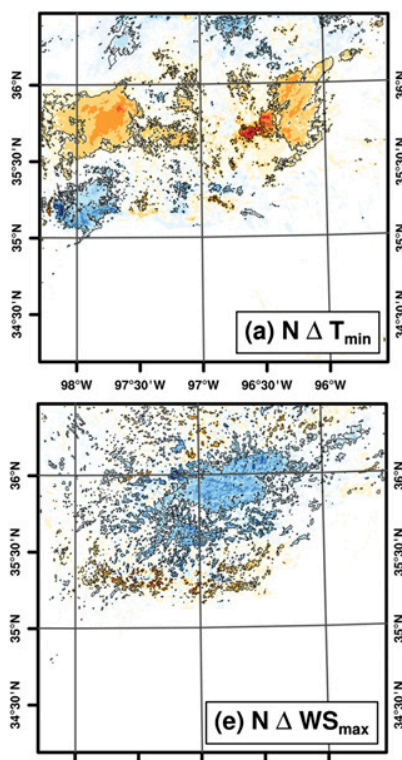

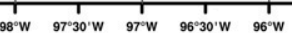
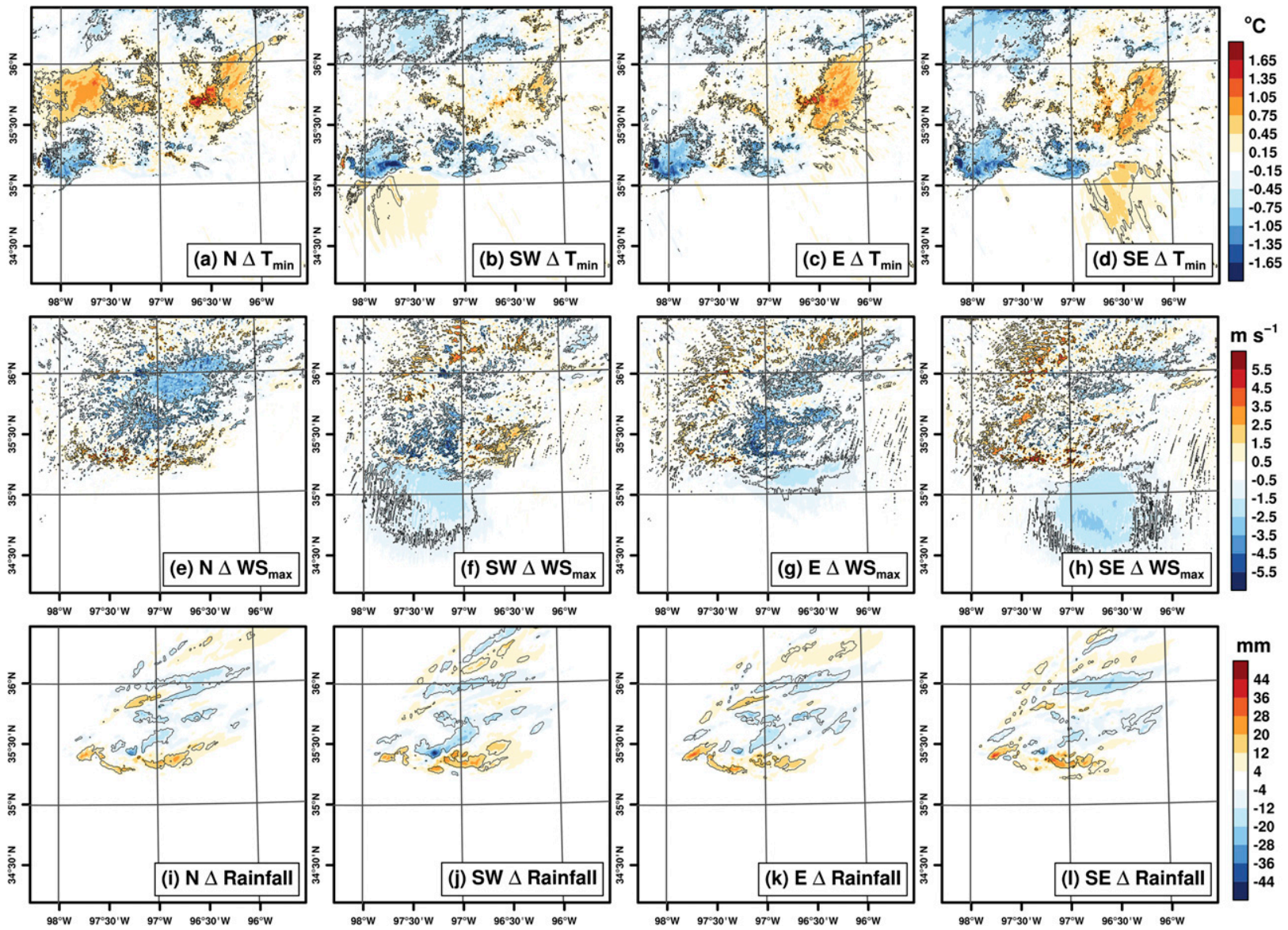

$\mathrm{m} \mathrm{s}^{-1}$
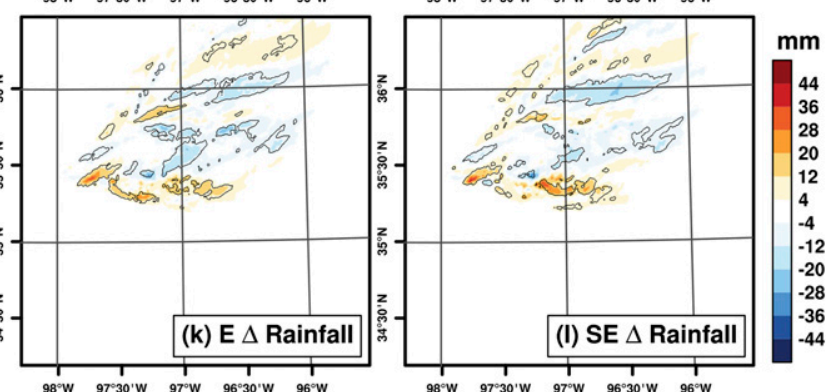

FIG. 15. As in Fig. 13, but for (a)-(d) difference in entire simulation time-composite minimum near-surface temperature $\left(T_{\min } ;{ }^{\circ} \mathrm{C}\right),(\mathrm{e})-(\mathrm{h})$ difference in time-composite maximum near-surface wind speed $\left(\mathrm{WS}_{\max } ; \mathrm{m} \mathrm{s}^{-1}\right)$, and (i)-(l) total accumulated rainfall (mm).

CTRL simulation, all urban groups end with no or negative net accumulated midlevel mesocyclone strength. Greater differences exist across the groups in low-level mesocyclone strength (Fig. 16b). The $\mathrm{N}$ and SE groups end the simulation with $\sim 12 \%-15 \%$ more accumulated low-level $\mathrm{UH}$, a majority of which is acquired during and after the formation of the new mesocyclone. While groups $\mathrm{E}$ and SW also finish with more accumulated 0-1-km UH than
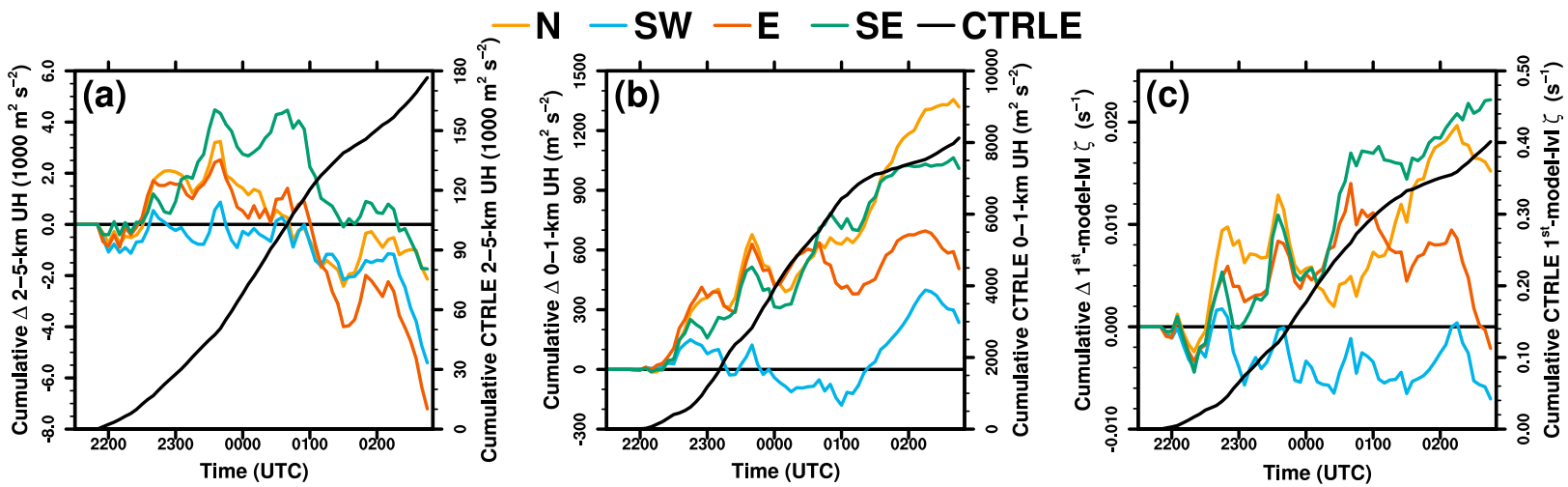

FIG. 16. Cumulative CTRLE group average (black) and accumulated difference from CTRLE of N (yellow), SW (blue), E (red), and SE (green) groups of the average of the mesocyclone's top 50\% highest values of (a) 2-5-km UH, (b) 0-1-km UH, and (c) first-model-level $\zeta$ as a function of time. 
CTRLE, their increase is smaller, particularly for the SW group. Similarly, the SE and $\mathrm{N}$ groups end with a greater increase in near-surface vertical vorticity (Fig. 16c) than do groups E and SW, though these are smaller increases over CTRLE than are present for $0-1-\mathrm{km} \mathrm{UH} \mathrm{(} \mathrm{5 \% ).} \mathrm{How-}$ ever, around the time that the mesocyclone cycles, the SE group simulations reach an increase in near-surface $\zeta$ over CTRLE of $\sim 8 \%-10 \%$. Contrastingly, the $\mathrm{N}$ group supercells accumulate their increased near-surface $\zeta$ later in the simulation, corresponding to the time of stronger 0-1-km UH (Fig. 16b). Across these measures of storm strength, the SW group generally has the weakest midand low-level mesocyclone strength, and correspondingly weak near-surface vorticity, particularly from 2200 to 0100 UTC, trends that are not apparent from Fig. 13.

\section{c. Storm inflow differences}

To diagnose possible inflow differences among the groups that may result in the storm modifications discussed in the previous section, we analyze meridional averages of inflow characteristics as a function of time and longitude, computed over box I in Fig. 5d (Figs. 17, 18). Changes to the thermal properties of the environment to the south of the storm are apparent in the SW, E, and SE groups. The western (eastern) half of the inflow region is warmer (Figs. 17a-d) and drier (Figs. 17e-h) than in CTRLE before the storm passes, when the city is in the southwestern (eastern and southeastern) portion of the domain. These warm and dry conditions result in higher LCL heights (Figs. 17i-1) and lower CAPE (Figs. 17m-p) near the city location, but these differences are generally neutralized as the storm approaches. Air to the west of the CTRL track is also cooler for the SW, E, and SE groups (Figs. 17b-d) because of the more southerly track of the mesocyclone in these groups. However, when the city is to the north of the storm (Figs. 17a,e,i,m), the thermal properties of the inflow are very similar to those of CTRLE throughout the lifetime of the storm.

Modifications to vertical shear and near-surface properties of the wind in the storm's inflow region are also evident when the storm is in the SW, E, and SE portions of the domain. Winds are generally slower in the inflow region of these groups' storms (Figs. 18b-d), likely a result of increased surface roughness in the urban area upstream of the mesocyclone. In agreement with the wind direction changes north of the city prior to storm formation (Fig. 7d)-which were hypothesized to be evidence of a building-barrier effect of the urban area-inflow-region, near-surface winds are generally veered when the city is to the east (Fig. 18g) or southeast (Fig. 18h) of the storm, but backed when the city is to the southwest (Fig. 18f) of the supercell. This is particularly evident during the latter half of the mesocyclone track for the SW group (Fig. 18h). These near-surface wind vector modifications result in higher inflow 0-1-km SRH (Figs. 18i-1), 0-500-m bulk shear (Figs. 18m-p), and firstmodel-level streamwise vorticity $\left(\zeta_{\text {sw }}\right.$; Figs. $\left.18 \mathrm{q}-\mathrm{s}\right)$. While few of these inflow descriptors differ from CTRLE ahead (i.e., to the east) of the storm when the city is to its north, some parameters, particularly SRH and wind direction near the ground, are quite different very near and behind (i.e., to the west of) the mesocyclone.

\section{Summary and conclusions}

In this study, we used the WRF to analyze the effect of a large southern plains urban area (DFW) on an isolated supercell. To investigate how urban-storm interactions change with varying city-relative storm tracks, DFW was placed in 108 systematically chosen locations, resulting in 108 unique simulations. Hierarchical clustering analysis was used to determine which simulation members were most similar to each other, providing groups of simulations, which were compared to each other.

First-order urban effects were clear prior to storm formation. Results generally agree with prior observations of urban areas, with warmer and drier near-surface air over and downwind of the city, accompanied by slower near-surface wind speeds. Decreased winds near the surface resulted in an approximate $50 \%$ increase in $0-1-\mathrm{km}$ SRH over the urban area.

HCA results indicated that storm-total rainfall was not statistically dependent upon city location. However, total accumulated rainfall generally increased across all urban simulations, regardless of city location, though no discernible pattern differences in precipitation changes were evident. This result suggests that urbanization impacts on a strongly forced system, though apparent, may be more evidenced by general rainfall amplification or nuanced pattern changes as opposed to the clear over and downwind urban precipitation increases observed under synoptically benign regimes (e.g., Shepherd et al. 2010; Li et al. 2011; Niyogi et al. 2011). Other studies that have considered strongly forced and flow-dependent events (e.g., Yang et al. 2014a; McLeod et al. 2017) have also noted only subtle or disorganized changes in precipitation amounts and distribution.

Similarly, HCA results for $2-5-\mathrm{km}$ UH provided groups of simulations with widely scattered urban locations, though some differences from CTRLE were apparent across all simulations. Urban simulations, on average, had greater 2-5-km UH associated with the second mesocyclone, which tended to track farther south than in CTRLE simulations. These deviations 

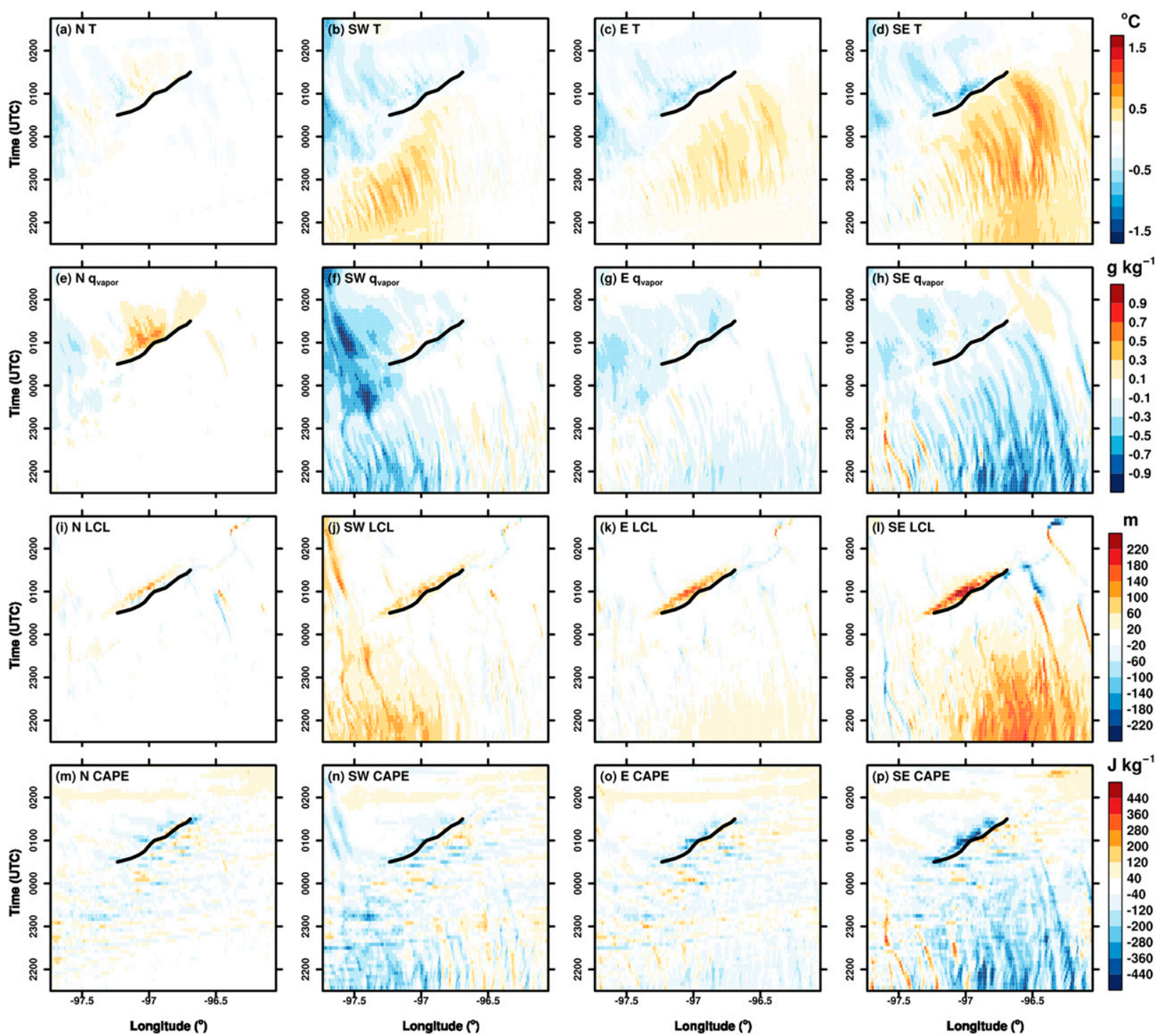

FIG. 17. (a) Hovmöller diagram of meridionally averaged first-model-layer differences in group $\mathrm{N} T\left({ }^{\circ} \mathrm{C}\right)$ from CTRLE computed over box I (Figs. 13e-h), with time (UTC) on the ordinate and longitude $\left(^{\circ}\right)$ on the abscissa. The thick black line represents the southern-most CTRL storm mesocyclone track in longitude-time space. (b)-(d) As in (a), but for groups SW, E, and SE, respectively. (e)-(h) As in (a)-(d), but for differences in first-model-level water vapor mixing ratio $\left(q ; \mathrm{g} \mathrm{kg}^{-1}\right)$. (i)-(l) As in (a)-(d), but for differences in LCL height (m). (m)-(p) As in (a)-(d), but for differences in CAPE $\left(\mathrm{J} \mathrm{kg}^{-1}\right)$.

were most significant when the city was to the southeast and east of the storm, resulting in city-storm interaction later in the storm's lifetime. It is possible that the simple presence of the urban area anywhere within the domain leads to a general increase in SRH and instability throughout the domain, resulting in stronger storms on average, particularly when the urban area is south and east of the storm.

In contrast, clusters resultant from HCA of $0-1-\mathrm{km}$ $\mathrm{UH}$, near-surface maximum wind speed, and nearsurface minimum temperature each contained simulations with similarly located urban areas, suggesting that low-level storm characteristics and impacts are more dependent on city location. Simulations with city locations of similar east-west location generally were more alike than those with similar north-south locations. This order of similarity suggests that low-level supercell characteristics are most sensitive to the north-south location of a city relative to the storm path. Indicators of storm strength and evolution were also modulated by the city.

Time series analyses suggested that mesocyclones of simulations with city locations to the southeast and east of the storm track accumulated $\sim 15 \%$ more $0-1-\mathrm{km} \mathrm{UH}$ 

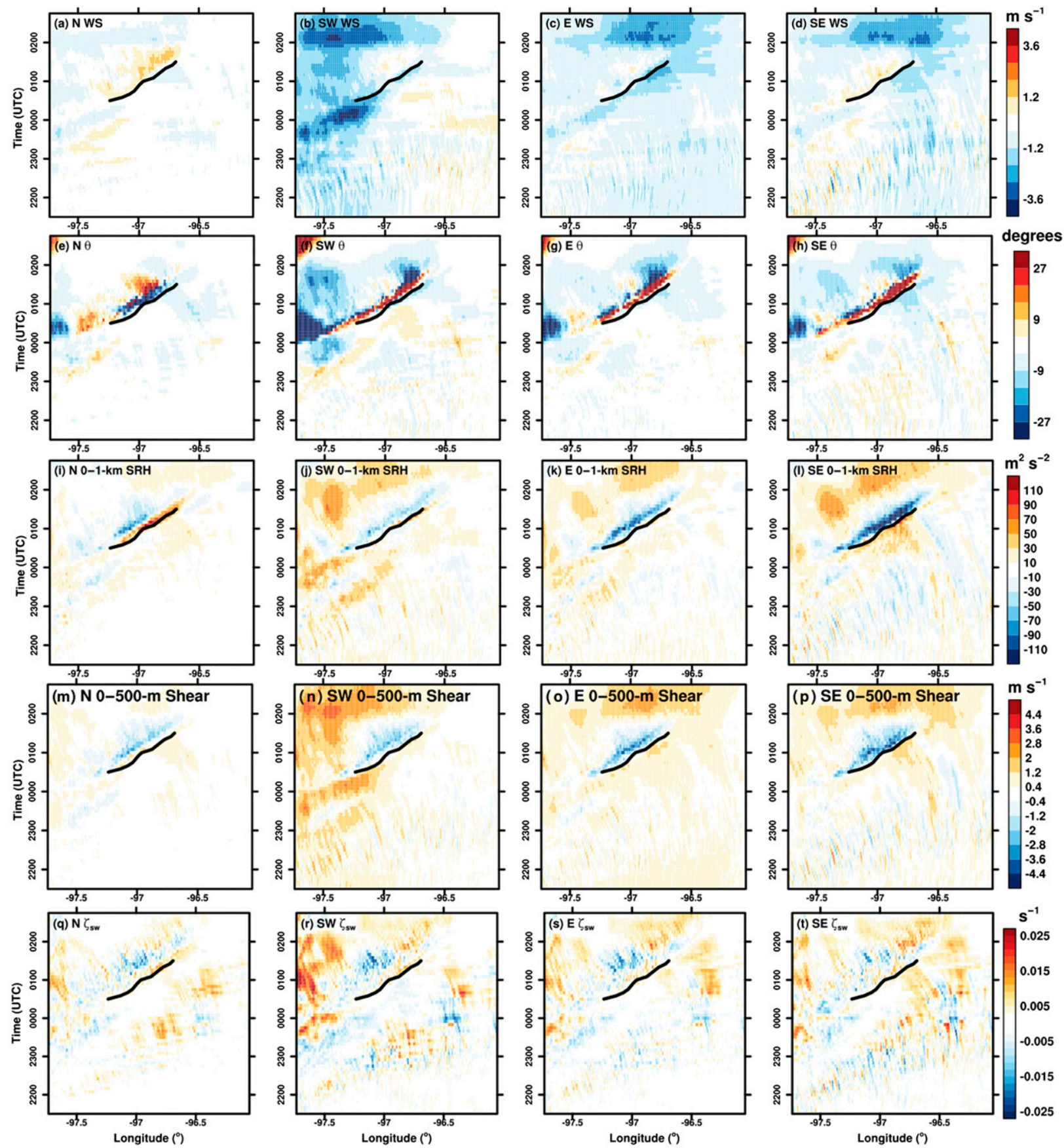

FIG. 18. As in Fig. 17, but for differences in (a)-(d) first-model-level WS $\left(\mathrm{m} \mathrm{s}^{-1}\right)$; (e)-(h) first-model-level wind direction $\left(\theta ;^{\circ}\right)$; (i)-(l) 0-1-km SRH $\left(\mathrm{m}^{2} \mathrm{~s}^{-1}\right) ;(\mathrm{m})-(\mathrm{p}) 0-500-\mathrm{m}$ bulk shear $\left(\mathrm{m} \mathrm{s}^{-1}\right)$; and $(\mathrm{q})-(\mathrm{t})$ first-model-level streamwise vorticity $\left(\zeta_{\mathrm{sw}} ; \mathrm{s}^{-1}\right)$.

than CTRLE by the end of the CTRL supercell's lifetime ( $\sim 0200$ UTC). While it appears that most storms in these simulations had also dissipated by this time, simulations with cities to the north of the main supercell storm continued to accumulate more $0-1-\mathrm{km}$ UH after $\sim 0200$ UTC and ended with $\sim 30 \%$ more accumulated $0-1-\mathrm{km}$ UH. Given that the main supercell in CTRL has essentially dissipated by 0200 UTC, this increase in mesocyclone strength at the end of the simulation is likely associated with the significant increase in mesocyclone tracks east of the eastern-most CTRL track (Fig. 5). This suggests that in simulations with urban areas north of the general storm track, storms maintained strength for longer as they began interacting with 
the southern edge of the urban area. Contrary to these results, simulations where the supercell tracked north of or over the city early in its lifetime (i.e., the southwest group) had the smallest increase in mid- and low-level mesocyclone strength and had weaker near-surface rotation, compared to CTRLE, indicating a detrimental effect of the urban area on the developing storm.

The storm's inflow region was warmer and slower near the surface for simulations with city locations to the south of the storm track. The inflow is also more sheared in the lowest $1 \mathrm{~km}$ AGL in these simulations. However, inflow differences were more limited when the storm moved south of the urban area. Hence, it is clear that the urban area is having a direct effect on the storm's inflow. These results, combined with analyses of prestorm urban effects that indicated warmer, drier, higher-shear conditions over and north of the urban area, indicate that when the city is in the storm's general inflow region (i.e., south and east of the storm), urban influences on a storm's inflow remain consistent even as the storm modifies its own environment. Further work could involve parcel trajectory analyses to determine exactly how the storm's inflow is modified by the urban area and how these modifications contribute to storm strength and mesocyclone track.

While HCA has been used previously for attribution of variations in synoptic and mesoscale fields to various factors, this is the first time it has been used to analyze storm-scale modifications. Given their large scale of motion, synoptic and mesoscale phenomena are generally more predictable than severe storms; thus, few simulations are required to attribute large-scale field variations to modifications in boundary conditions and parameterization options. However, to perform attribution of small-scale effects to various factors in a real data simulation, many simulations are required to ensure that the simulated changes are significant. The general hindrance to such an analysis is the large computational requirement. However, as computational power continues to improve, such barriers will be removed. Given the successful use of HCA in the present work, future investigations of cause-and-effect relationships in small-scale phenomena are encouraged to use such a technique. For example, some recent research (e.g., Bosart et al. 2006; Markowski and Dotzek 2011) has investigated the effect of complex terrain on tornadogenesis and tornado maintenance, with the results suggesting that terrain effects are quite complex. Such a problem could be further investigated by performing HCA on a large number of fine-grid simulations. These kinds of investigations are also pertinent to the Warnon-Forecast (Stensrud et al. 2009) effort, as correctly predicting finescale interactions could prove critical to forecasting a storm's severe potential.
In comparison to studies on the effects of the urban area on weakly forced convection (i.e., Bornstein and Lin 2000; Shepherd et al. 2002, 2010; Niyogi et al. 2011), precipitation patterns in the simulations presented here were not well correlated with urban location, as suggested by the highly varied HCA group city locations. This finding does agree, though, with those of studies that consider convective systems in synoptically active regimes, where negligible largescale differences are found to be associated with the presence of urban areas (Yang et al. 2014a; Yeung et al. 2015; Ryu et al. 2016). Combined with these previous findings, the results presented here suggest that organized convective processes are less susceptible, on a large scale, to the effects of urban areas, but that storm-scale deviations (e.g., mesocyclone strength and track) can be modified by a large urban area.

Some previous studies that evaluate the effect of urban areas on precipitation patterns have hypothesized that the UHI can result in increased precipitation downwind of cities, while others suggest that urban surface roughness may cause precipitation to bifurcate around the city. In other words, both thermal and roughness properties of the urban area might be important in modifying convection. The present work does not evaluate these effects separately; therefore, we cannot determine exactly which aspects of the urban area are causing storm modifications. However, the results presented here suggest that both temperature and wind speed are modified in the storm's vicinity and inflow across all urban simulations, though the amount of each varied with city location. It is possible that the relative importance of urban thermal and dynamic influences on storm strength and evolution varies depending on the city's location in relation to the storm's path. Future work will involve a factor separation approach to investigate this possibility. Additional work should also include analyses of the effect of urban aerosols on simulated storms, as studies have proposed that urban aerosols can modulate storm microphysical properties, of which one consequence may be the induction of lightning maxima over and downwind of cities (e.g., Orville et al. 2001; Rose et al. 2008; Kar et al. 2009; Coquillat et al. 2013; Tan et al. 2016; Kawecki et al. 2016).

Acknowledgments. This research was supported in part by the NASA Interdisciplinary Science program Grant NNX12AM89G. Parts of this research were performed while the author held an NRC Research Associateship award at NOAA's National Severe Storms Laboratory. This research is also part of the Blue Waters sustained-petascale computing project, which is supported 
by the National Science Foundation (Awards OCI0725070 and ACI-1238993) and the state of Illinois. Blue Waters is a joint effort of the University of Illinois at Urbana-Champaign and its National Center for Supercomputing Applications. We want to thank Jess Walker for acquiring and processing NLCD data that were used in these simulations. We would also like to thank Dr. Kim Elmore, whose insight led directly to the use of hierarchical clustering analysis in this work.

\section{REFERENCES}

Ackerman, B., 1987: Climatology of Chicago area urban-rural differences in humidity. J. Appl. Meteor. Climatol., 26, 427-430, https:// doi.org/10.1175/1520-0450(1987)026<0427:COCAUR>2.0.CO;2.

Alhamed, A., S. Lakshmivarahan, and D. J. Stensrud, 2002: Cluster analysis of multimodel ensemble data from SAMEX. Mon. Wea. Rev., 130, 226-256, https://doi.org/10.1175/1520-0493 (2002)130<0226:CAOMED > 2.0.CO;2.

Alonso, M., M. Fidalgo, and J. Labajo, 2007: The urban heat island in Salamanca (Spain) and its relationship to meteorological parameters. Climate Res., 34, 39-46, https://doi.org/10.3354/ cr034039.

Anderberg, M. R., 1973: Cluster Analysis for Applications. Academic Press, 359 pp.

Arnfield, A. J., 2003: Two decades of urban climate research: A review of turbulence, exchanges of energy and water, and the urban heat island. Int. J. Climatol., 23, 1-26, https://doi.org/ 10.1002/joc.859.

Baik, J.-J., Y.-H. Kim, J.-J. Kim, and J.-Y. Han, 2007: Effects of boundary-layer stability on urban heat island-induced circulation. Theor. Appl. Climatol., 89, 73-81, https://doi.org/ 10.1007/s00704-006-0254-4.

Barlow, J. F., 2014: Progress in observing and modelling the urban boundary layer. Urban Climate, 10, 216-240, https://doi.org/ 10.1016/j.uclim.2014.03.011.

Bornstein, R. D., and D. S. Johnson, 1977: Urban-rural wind velocity differences. Atmos. Environ., 11, 597-604, https:// doi.org/10.1016/0004-6981(77)90112-3.

— and Q. Lin, 2000: Urban heat islands and summertime convective thunderstorms in Atlanta: Three case studies. Atmos. Environ., 34, 507-516, https://doi.org/10.1016/S1352-2310(99)00374-X.

Bosart, L. F., A. Seimon, K. D. LaPenta, and M. J. Dickinson, 2006: Supercell tornadogenesis over complex terrain: The Great Barrington, Massachusetts, tornado on 29 May 1995. Wea. Forecasting, 21, 897-922, https://doi.org/10.1175/WAF957.1.

Branković, Č., B. Matjačić, S. Ivatek-Šahdan, and R. Buizza, 2008: Downscaling of ECMWF ensemble forecasts for cases of severe weather: Ensemble statistics and cluster analysis. Mon. Wea. Rev., 136, 3323-3342, https://doi.org/10.1175/2008MWR2322.1.

Burian, S. J., W. S. Han, and M. J. Brown, 2005: Morphological analyses using 3D building databases: Oklahoma City, Oklahoma. Los Alamos National Laboratory Rep. LA-UR-05-1821, 63 pp.

Chappell, C. F., 1986: Quasi-stationary convective events. Mesoscale Meteorology and Forecasting, P. Ray, Ed., Amer. Meteor. Soc., 289-310, https://doi.org/10.1007/978-1-935704-20-1_13.

Chen, F., and J. Dudhia, 2001: Coupling an advanced land surfacehydrology model with the Penn State-NCAR MM5 modeling system. Part I: Model implementation and sensitivity. Mon. Wea. Rev., 129, 569-585., https://doi.org/10.1175/1520-0493 (2001) $129<0569$ :CAALSH>2.0.CO;2.
Chou, M. D., and M. J. Suarez, 1999: A solar radiation parameterization for atmospheric studies. NASA Tech. Rep. Series on Global Modeling and Data Assimilation NASA/TM-1999104606, 38 pp., http://gmao.gsfc.nasa.gov/pubs/docs/Chou136.pdf. X. Z. Liang, and M. M. H. Yan, 2001: A thermal infrared radiation parameterization for atmospheric studies. NASA Tech. Rep. Series on Global Modeling and Data Assimilation NASA/TM-2001-104606, 68 pp., http://ntrs.nasa.gov/ archive/nasa/casi.ntrs.nasa.gov/20010072848.pdf.

Clark, A. J., and Coauthors, 2012: An overview of the 2010 Hazardous Weather Testbed experimental forecast program spring experiment. Bull. Amer. Meteor. Soc., 93, 55-74, https:// doi.org/10.1175/BAMS-D-11-00040.1.

- M. C. Coniglio, B. E. Coffer, G. Thompson, M. Xue, and F. Kong, 2015: Sensitivity of 24-h forecast dryline position and structure to boundary layer parameterizations in convectionallowing WRF Model simulations. Wea. Forecasting, 30, 613-638, https://doi.org/10.1175/WAF-D-14-00078.1.

Coniglio, M. C., J. Correia, P. T. Marsh, and F. Kong, 2013: Verification of convection-allowing WRF Model forecasts of the planetary boundary layer using sounding observations. Wea. Forecasting, 28, 842-862, https://doi.org/10.1175/WAF-D-1200103.1.

Coquillat, S., M.-P. Boussaton, M. Buguet, D. Lambert, J.-F. Ribaud, and A. Berthelot, 2013: Lightning ground flash patterns over Paris area between 1992 and 2003: Influence of pollution? Atmos. Res., 122, 77-92, https://doi.org/10.1016/ j.atmosres.2012.10.032.

Dou, J., Y. Wang, R. Bornstein, and S. Miao, 2015: Observed spatial characteristics of Beijing urban climate impacts on summer thunderstorms. J. Appl. Meteor. Climatol., 54, 94-105, https://doi.org/10.1175/JAMC-D-13-0355.1.

Dyer, A. J., and B. B. Hicks, 1970: Flux-gradient relationships in the constant flux layer. Quart. J. Roy. Meteor. Soc., 96, 715-721, https://doi.org/10.1002/qj.49709641012.

Ek, M. B., K. E. Mitchell, Y. Lin, E. Rogers, P. Grunmann, V. Koren, G. Gayno, and J. D. Tarpley, 2003: Implementation of Noah land surface model advances in the National Centers for Environmental Prediction operational mesoscale Eta model. J. Geophys. Res., 108, 8851, https://doi.org/10.1029/2002JD003296.

Esterheld, J. M., and D. J. Giuliano, 2008: Discriminating between tornadic and non-tornadic supercells: A new hodograph technique. Electron. J. Severe Storms Meteor., 3 (2), 1-50.

Ganeshan, M., R. Murtugudde, and M. L. Imhoff, 2013: A multi-city analysis of the UHI-influence on warm season rainfall. Urban Climate, 6, 1-23, https://oi.org/10.1016/j.uclim.2013.09.004.

Gedzelman, S. D., S. Austin, R. Cermak, N. Stefano, S. Partridge, S. Quesenberry, and D. A. Robinson, 2003: Mesoscale aspects of the urban heat island around New York City. Theor. Appl. Climatol., 75, 29-42, https://doi.org/10.1007/s00704-002-0724-2.

Hage, K. D., 1975: Urban-rural humidity differences. J. Appl. Meteor., 14, 1277-1283, https://doi.org/10.1175/1520-0450 (1975) $014<1277:$ URHD $>2.0$. CO;2.

Homer, C., and Coauthors, 2015: Completion of the 2011 National Land Cover Database for the conterminous United StatesRepresenting a decade of land cover change information. Photogramm. Eng. Remote Sensing, 81 (5), 346-354.

Howells, P. A. C., R. Rotunno, and R. K. Smith, 1988: A comparative study of atmospheric and laboratory-analogue numerical tornado-vortex models. Quart. J. Roy. Meteor. Soc., 114, 801-822, https://doi.org/10.1002/qj.49711448113.

Hu, X.-M., M. Xue, P. M. Klein, B. G. Illston, and S. Chen, 2016: Analysis of urban effects in Oklahoma City using a dense 
surface observing network. J. Appl. Meteor. Climatol., 55, 723741, https://doi.org/10.1175/JAMC-D-15-0206.1.

Johns, R. H., and C. A. Doswell III, 1992: Severe local storms forecasting. Wea. Forecasting, 7, 588-612, https://doi.org/ 10.1175/1520-0434(1992)007<0588:SLSF $>2.0 . C O ; 2$.

Johnson, A., X. Wang, F. Kong, and M. Xue, 2011a: Hierarchical cluster analysis of a convection-allowing ensemble during the Hazardous Weather Testbed 2009 Spring Experiment. Part I: Development of the object-oriented cluster analysis method for precipitation fields. Mon. Wea. Rev., 139, 3673-3693, https://doi.org/10.1175/MWR-D-11-00015.1.

_, — M. Xue, and F. Kong, 2011b: Hierarchical cluster analysis of a convection-allowing ensemble during the Hazardous Weather Testbed 2009 Spring Experiment. Part II: Ensemble clustering over the whole experiment period. Mon. Wea. Rev., 139, 3694-3710, https://doi.org/10.1175/MWR-D-11-00016.1.

Kain, J. S., and Coauthors, 2008: Some practical considerations regarding horizontal resolution in the first generation of operational convection-allowing NWP. Wea. Forecasting, 23, 931-952, https://doi.org/10.1175/WAF2007106.1.

Kar, S., Y.-A. Liou, and K.-J. Ha, 2009: Aerosol effects on the enhancement of cloud-to-ground lightning over major urban areas of South Korea. Atmos. Res., 92, 80-87, https://doi.org/ 10.1016/j.atmosres.2008.09.004.

Kawecki, S., G. M. Henebry, and A. L. Steiner, 2016: Effects of urban plume aerosols on a mesoscale convective system. J. Atmos. Sci., 73, 4641-4660, https://doi.org/10.1175/JAS-D16-0084.1.

Kusaka, H., and F. Kimura, 2004: Thermal effects of urban canyon structure on the nocturnal heat island: Numerical experiment using a mesoscale model coupled with an urban canopy model. J. Appl. Meteor., 43, 1899-1910, https://doi.org/10.1175/ JAM2169.1.

— - H. Kondo, Y. Kikegawa, and F. Kimura, 2001: A simple single-layer urban canopy model for atmospheric models: Comparison with multi-layer and slab models. Bound.-Layer Meteor., 101, 329-358, https://doi.org/10.1023/A:1019207923078.

Lacke, M. C., T. Mote, and J. M. Shepherd, 2009: Aerosols and associated precipitation patterns in Atlanta. Atmos. Environ., 43, 4359-4373, https://doi.org/10.1016/j.atmosenv.2009.04.022.

Landsberg, H. E., 1981: The Urban Climate. Academic Press, 275 pp.

Lee, D., 1991: Urban-rural humidity differences in London. Int J. Climatol., 11, 577-582, https://doi.org/10.1002/joc.3370110509.

Lewellen, W. S., 1993: Tornado vortex theory. The Tornado: Its Structure, Dynamics, Prediction, and Hazards, Geophys. Monogr., Vol. 79, Amer. Geophys. Union, 19-39.

Li, W., S. Chen, G. Chen, W. Sha, C. Luo, Y. Feng, Z. Wen, and B. Wang, 2011: Urbanization signatures in strong versus weak precipitation over the Pearl River Delta metropolitan regions of China. Environ. Res. Lett., 6, 049503, https://doi.org/ 10.1088/1748-9326/6/4/049503.

Loose, T., and R. D. Bornstein, 1977: Observations of mesoscale effects on frontal movement through an urban area. Mon. Wea. Rev., 105, 563-571, https://doi.org/10.1175/1520-0493 (1977) $105<0563$ :OOMEOF $>2.0 . C O ; 2$.

Mansell, E. R., C. L. Ziegler, and E. C. Bruning, 2010: Simulated electrification of a small thunderstorm with two-moment bulk microphysics. J. Atmos. Sci., 67, 171-194, https://doi.org/ 10.1175/2009JAS2965.1.

Markowski, P. M., and N. Dotzek, 2011: A numerical study of the effects of orography on supercells. Atmos. Res., 100, 457-478, https://doi.org/10.1016/j.atmosres.2010.12.027.
— and Y. P. Richardson, 2014: The influence of environmental low-level shear and cold pools on tornadogenesis: Insights from idealized simulations. J. Atmos. Sci., 71, 243-275, https:// doi.org/10.1175/JAS-D-13-0159.1.

- and Coauthors, 2012: The pretornadic phase of the Goshen County, Wyoming, supercell of 5 June 2009 intercepted by VORTEX2. Part II: Intensification of low-level rotation. Mon. Wea. Rev., 140, 2916-2938, https://doi.org/10.1175/MWR-D-11-00337.1.

Matsui, T., W. K. Tao, and R. Shi, 2007: Goddard radiation and aerosol direct effect in Goddard WRF. NASA/UMD WRF Workshop, College Park, Maryland, NASA and University of Maryland, College Park, 12 pp.

McLeod, J., M. Shepherd, and C. E. Konrad, 2017: Spatio-temporal rainfall patterns around Atlanta, Georgia and possible relationships to urban land cover. Urban Climate, 21, 27-42, https://doi.org/10.1016/j.uclim.2017.03.004.

Miao, S., F. Chen, Q. Li, and S. Fan, 2011: Impacts of urban processes and urbanization on summer precipitation: A case study of heavy rainfall in Beijing on 1 August 2006. J. Appl. Meteor. Climatol., 50, 806-825, https://doi.org/10.1175/2010JAMC2513.1.

Monin, A. S., and A. M. Obukhov, 1954: Basic laws of turbulent mixing in the surface layer of the atmosphere. Contrib. Geophys. Inst. Acad. Sci. USSR, 24 (151), 163-187.

Mote, T. L., M. C. Lacke, and J. M. Shepherd, 2007: Radar signatures of the urban effect on precipitation distribution: A case study for Atlanta, Georgia. Geophys. Res. Lett., 34, L20710, https://doi.org/10.1029/2007GL031903.

Murtagh, F., and P. Legendre, 2014: Ward's hierarchical agglomerative clustering method: Which algorithms implement Ward's criterion? J. Classif., 31 (3), 274-295, https://doi.org/ 10.1007/s00357-014-9161-z.

Nakaegawa, T., and M. Kanamitsu, 2006: Cluster analysis of the seasonal forecast skill of the NCEP SFM over the PacificNorth America sector. J. Climate, 19, 123-138, https://doi.org/ 10.1175/JCLI3609.1.

Niyogi, D., P. Pyle, M. Lei, S. P. Arya, C. M. Kishtawal, M. Shepherd, F. Chen, and B. Wolfe, 2011: Urban modification of thunderstorms: An observational storm climatology and model case study for the Indianapolis urban region. J. Appl. Meteor. Climatol., 50, 1129-1144, https://doi.org/ 10.1175/2010JAMC1836.1

Noh, Y., W. G. Cheon, S. Y. Hong, and S. Raasch, 2003: Improvement of the k-profile model for the planetary boundary layer based on large eddy simulation data. Bound.-Layer Meteor., 107, 401-427, https://doi.org/10.1023/A:1022146015946.

Nowotarski, C. J., and A. A. Jensen, 2013: Classifying proximity soundings with self-organizing maps toward improving supercell and tornado forecasting. Wea. Forecasting, 28, 783801, https://doi.org/10.1175/WAF-D-12-00125.1.

Oke, T. R., 1976: The distinction between canopy and boundarylayer urban heat islands. Atmosphere, 14 (4), 268-277.

, 1981: Canyon geometry and the nocturnal urban heat island: Comparison of scale model and field observations. J. Climatol., 1, 237-254, https://doi.org/10.1002/joc.3370010304.

, 1982: The energetic basis of the urban heat island. Quart. J. Roy. Meteor. Soc., 108, 1-24, https://doi.org/10.1002/qj.49710845502.

Orville, R. E., and Coauthors, 2001: Enhancement of cloud-toground lightning over Houston, Texas. Geophys. Res. Lett., 28 , 2597-2600, https://doi.org/10.1029/2001GL012990.

Paulson, C. A., 1970: The mathematical representation of wind speed and temperature profiles in the unstable atmospheric surface layer. J. Appl. Meteor., 9, 857-861, https://doi.org/ 10.1175/1520-0450(1970)009<0857:TMROWS>2.0.CO;2. 
Pitman, E., 1938: Significance tests which may be applied to samples from any populations: III. The analysis of variance test. Biometrika, 29, 322-335, https://doi.org/10.2307/2332008.

Reames, L. J., and D. J. Stensrud, 2017: Sensitivity of simulated urban-atmosphere interactions in Oklahoma City to urban parameterization. J. Appl. Meteor. Climatol., 56, 1405-1430, https://doi.org/10.1175/JAMC-D-16-0223.1.

Rose, L. S., J. A. Stallins, and M. L. Bentley, 2008: Concurrent cloud-to-ground lightning and precipitation enhancement in the Atlanta, Georgia (United States), urban region. Earth Interact., 12, https://doi.org/10.1175/2008EI265.1.

Rotunno, R., 1979: A study in tornado-like vortex dynamics. J. Atmos. Sci., 36, 140-155, https://doi.org/10.1175/15200469(1979)036<0140:ASITLV > 2.0.CO;2.

Ryu, Y.-H., J. A. Smith, E. Bou-Zeid, and M. L. Baeck, 2016: The influence of land surface heterogeneities on heavy convective rainfall in the Baltimore-Washington metropolitan area. Mon. Wea. Rev., 144, 553-573, https://doi.org/10.1175/ MWR-D-15-0192.1.

Schenkman, A. D., M. Xue, and A. Shapiro, 2012: Tornadogenesis in a simulated mesovortex within a mesoscale convective system. J. Atmos. Sci., 69, 3372-3390, https://doi.org/10.1175/ JAS-D-12-038.1.

Seino, N., T. Aoyagi, and H. Tsuguti, 2018: Numerical simulation of urban impact on precipitation in Tokyo: How does urban temperature rise affect precipitation? Urban Climate, 23, 8-35, https://doi.org/10.1016/j.uclim.2016.11.007.

Shepherd, J. M., 2006: Evidence of urban-induced precipitation variability in arid climate regimes. J. Arid Environ., 67, 607-628, https://doi.org/10.1016/j.jaridenv.2006.03.022.

— , and S. J. Burian, 2003: Detection of urban-induced rainfall anomalies in a major coastal city. Earth Interact., 7, https://doi.org/ 10.1175/1087-3562(2003)007<0001:DOUIRA > 2.0.CO;2.

-, H. Pierce, and A. J. Negri, 2002: Rainfall modification by major urban areas: Observations from spaceborne rain radar on the TRMM satellite. J. Appl. Meteor., 41, 689-701, https://doi.org/ 10.1175/1520-0450(2002)041<0689:RMBMUA>2.0.CO;2.

—, M. Carter, M. Manyin, D. Messen, and S. Burian, 2010: The impact of urbanization on current and future coastal precipitation: A case study for Houston. Environ. Plann., 37B, 284-304, https://doi.org/10.1068/b34102t.

Skamarock, W., and J. Klemp, 2008: A time-split nonhydrostatic atmospheric model for weather research and forecasting applications. J. Comput. Phys., 227, 3465-3485, https://doi.org/ 10.1016/j.jcp.2007.01.037.

Stensrud, D. J., and Coauthors, 2009: Convective-scale warn-onforecast system: A vision for 2020. Bull. Amer. Meteor. Soc., 90, 1487-1500, https://doi.org/10.1175/2009BAMS2795.1.

Tan, Y. B., L. Peng, Z. Shi, and H. R. Chen, 2016: Lightning flash density in relation to aerosol over Nanjing (China). Atmos. Res., 174-175, 1-8, https://doi.org/10.1016/j.atmosres.2016.01.009.

Thielen, J., W. Wobrock, A. Gadian, P. Mestayer, and J.-D. Creutin, 2000: The possible influence of urban surfaces on rainfall development: A sensitivity study in 2D in the meso$\gamma$-scale. Atmos. Res., 54, 15-39, https://doi.org/10.1016/S01698095(00)00041-7.

Thompson, R. L., and R. Edwards, 2000: An overview of environmental conditions and forecast implications of the 3 May 1999 tornado outbreak. Wea. Forecasting, 15, 682-699, https://doi.org/ 10.1175/1520-0434(2000)015<0682:AOOECA > 2.0.CO;2.

Togstad, W. E., J. M. Davies, S. J. Corfidi, D. R. Bright, and A. R. Dean, 2011: Conditional probability estimation for significant tornadoes based on Rapid Update Cycle (RUC) profiles.
Wea. Forecasting, 26, 729-743, https://doi.org/10.1175/ 2011WAF2222440.1.

Unkašević, M., O. Jovanović, and T. Popović, 2001: Urban-suburban/rural vapour pressure and relative humidity differences at fixed hours over the area of Belgrade city. Theor. Appl. Climatol., 68, 67-73, https://doi.org/10.1007/s007040170054.

Wang, X., J. Liao, J. Zhang, C. Shen, W. Chen, B. Xia, and T. Wang, 2014: A numeric study of regional climate change induced by urban expansion in the Pearl River Delta, China. J. Appl. Meteor. Climatol., 53, 346-362, https://doi.org/ 10.1175/JAMC-D-13-054.1.

Ward, J. H., 1963: Hierarchical grouping to optimize an objective function. J. Amer. Stat. Assoc, , 58, 236-244, https://doi.org/ 10.1080/01621459.1963.10500845.

Webb, E. K., 1970: Profile relationships: The log-linear range, and extension to strong stability. Quart. J. Roy. Meteor. Soc., 96, 67-90, https://doi.org/10.1002/qj.49709640708.

Wicker, L. J., 1996: The role of near-surface wind shear on lowlevel mesocyclone generation and tornadoes. Preprints, 18th Conf. on Severe Local Storms, San Francisco, CA, Amer. Meteor. Soc., 115-119.

Wilks, D. S., 2011: Statistical Methods in the Atmospheric Sciences. 3rd ed. International Geophysics Series, Vol. 100, Academic Press, 704 pp.

Xia, Y., and Coauthors, 2012: Continental-scale water and energy flux analysis and validation for the North American Land Data Assimilation System project phase 2 (NLDAS-2): 1. Intercomparison and application of model products. J. Geophys. Res., 117, D03109, https://doi.org/10.1029/2011JD016048.

_ J. Sheffield, M. B. Ek, J. Dong, N. Chaney, H. Wei, J. Meng, and E. F. Wood, 2014: Evaluation of multi-model simulated soil moisture in NLDAS-2. J. Hydrol., 512, 107-125, https:// doi.org/10.1016/j.jhydrol.2014.02.027.

Xian, G., C. Homer, J. Dewitz, J. Fry, N. Hossain, and J. Wickham, 2011: Change of impervious surface area between 2001 and 2006 in the conterminous United States. Photogramm. Eng. Remote Sens., 77, 758-762.

$\mathrm{Xu}, \mathrm{X}$., M. Xue, and Y. Wang, 2015: The genesis of mesovortices within a real-data simulation of a bow echo system. J. Atmos. Sci., 72, 1963-1986, https://doi.org/10.1175/JAS-D-14-0209.1.

Yang, L., J. A. Smith, M. L. Baeck, E. Bou-Zeid, S. M. Jessup, F. Tian, and H. Hu, 2014a: Impact of urbanization on heavy convective precipitation under strong large-scale forcing: A case study over the Milwaukee-Lake Michigan region. J. Hydrometeor., 15, 261-278, https://doi.org/10.1175/JHM-D-13-020.1.

_ F. Tian, J. A. Smith, and H. Hu, 2014b: Urban signatures in the spatial clustering of summer heavy rainfall events over the Beijing metropolitan region. J. Geophys. Res. Atmos., 119, 1203-1217, https://doi.org/10.1002/2013JD020762.

Yang, P., G. Ren, and W. Liu, 2013: Spatial and temporal characteristics of Beijing urban heat island intensity. J. Appl. Meteor. Climatol., 52, 1803-1816, https://doi.org/10.1175/JAMC-D-12-0125.1.

Yeung, J. K., J. A. Smith, M. L. Baeck, and G. Villarini, 2015: Lagrangian analyses of rainfall structure and evolution for organized thunderstorm systems in the urban corridor of the northeastern United States. J. Hydrometeor., 16, 1575-1595, https://doi.org/10.1175/JHM-D-14-0095.1.

Yow, D. M., and G. J. Carbone, 2006: The urban heat island and local temperature variations in Orlando, Florida. Southeast. Geogr., 46, 297-321, https://doi.org/10.1353/sgo.2006.0033.

Yussouf, N., D. J. Stensrud, and S. Lakshmivarahan, 2004: Cluster analysis of multimodel ensemble data over New England. Mon. Wea. Rev., 132, 2452-2462, https://doi.org/10.1175/ 1520-0493(2004)132<2452:CAOMED>2.0.CO;2. 